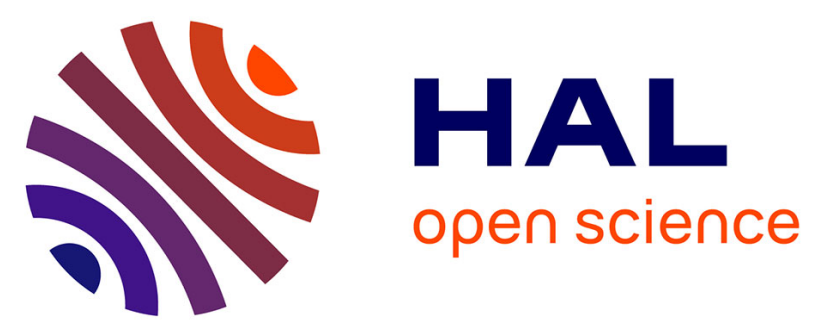

\title{
Low doses of uranium and osteoclastic bone resorption: key reciprocal effects evidenced using new in vitro biomimetic models of bone matrix
}

Tatiana Gritsaenko, Valérie Pierrefite-Carle, Gaëlle Creff, Bastien Simoneau, Agnès Hagège, Delphine Farlay, Sophie Pagnotta, François Orange, Xavier Jaurand, Christophe Den Auwer, et al.

\section{To cite this version:}

Tatiana Gritsaenko, Valérie Pierrefite-Carle, Gaëlle Creff, Bastien Simoneau, Agnès Hagège, et al.. Low doses of uranium and osteoclastic bone resorption: key reciprocal effects evidenced using new in vitro biomimetic models of bone matrix. Archives of Toxicology, 2021, 95 (3), pp.1023-1037. 10.1007/s00204-020-02966-1 . hal-03108237

\section{HAL Id: hal-03108237 https://hal.science/hal-03108237}

Submitted on 3 Nov 2021

HAL is a multi-disciplinary open access archive for the deposit and dissemination of scientific research documents, whether they are published or not. The documents may come from teaching and research institutions in France or abroad, or from public or private research centers.
L'archive ouverte pluridisciplinaire HAL, est destinée au dépôt et à la diffusion de documents scientifiques de niveau recherche, publiés ou non, émanant des établissements d'enseignement et de recherche français ou étrangers, des laboratoires publics ou privés. 


\section{Low doses of uranium and osteoclastic bone resorption: key reciprocal effects evidenced using new in vitro biomimetic models of bone matrix.}

Tatiana Gritsaenko¹, Valérie Pierrefite-Carle ${ }^{1}$, Gaëlle Creff $^{2}$, Bastien Simoneau ${ }^{1}$, Agnès Hagège $^{3}$, Delphine Farlay ${ }^{4}$, Sophie Pagnotta ${ }^{5}$, François Orange ${ }^{5}$, Xavier Jaurand ${ }^{6}$, Christophe Den Auwer ${ }^{2}$, Georges F. Carle ${ }^{1}$, Sabine Santucci-Darmanin ${ }^{1 *}$

1. Université Côte d'Azur, CEA, Institut Frédéric Joliot, TIRO-MATOs, 06107 Nice, France 2. Université Côte d'Azur, CNRS, Institut de Chimie de Nice, 06108 Nice, France

3. Université de Lyon, CNRS, Université Lyon 1, Institut des Sciences Analytiques, 69100 Villeurbanne, France

4. Université de Lyon, INSERM, Université Claude Bernard Lyon 1, LYOS UMR1033, F69008, Lyon, France

5. Université Côte d'Azur, Centre Commun de Microscopie Appliquée (CCMA), 06108 Nice, France

6. Université de Lyon, Université Claude Bernard Lyon 1, Centre Technologique des Microstructures, 5 rue Raphaël Dubois, 69622 Villeurbanne Cedex, France

${ }^{*}$ Corresponding author: Sabine Santucci-Darmanin

Email: $\underline{\text { santucci@unice.fr }}$

Phone: +33493377629

ORCIDs: https://orcid.org/0000-0001-5354-6988

Postal address: UMR E4320 TIRO-MATOs, Faculté de Médecine, 28 avenue de Valombrose, 06107 Nice, France 


\begin{abstract}
Uranium is widely spread in the environment due to its natural and anthropogenic occurrences, hence the importance of understanding its impact on human health. The skeleton is the main site of long-term accumulation of this actinide. However, interactions of this metal with biological processes involving the mineralized extracellular matrix and bone cells are still poorly understood. To get a better insight of these interactions, we developed new biomimetic bone matrices containing low doses of natural uranium (up to $0.85 \mu \mathrm{g}$ per $\mathrm{cm}^{2}$ of uranium). These models were characterized by spectroscopic and microscopic approaches before being used as a support for the culture and differentiation of preosteoclastic cells. In doing so, we demonstrate that uranium can exert opposite effects on osteoclast resorption depending on its concentration in the bone microenvironment. Our results also provide evidence for the first time that resorption contributes to the remobilization of bone matrix-bound uranium. In agreement with this, we identified, by HRTEM, uranium phosphate internalized in vesicles of resorbing osteoclasts. Thanks to the biomimetic matrices we developed, this study highlights the complex mutual effects between osteoclasts and uranium. This demonstrates the relevance of these 3D models to further study the cellular mechanisms at play in response to uranium storage in bone tissue and thus better understand the impact of environmental exposure to uranium on human bone health.
\end{abstract}

\title{
Keywords :
}

Uranium, Bone, Extracellular Matrix, Osteoclasts, Resorption, Biomimetic models 


\section{Declarations}

\section{Acknowledgements and Funding}

The authors would like to thank Chantal Cros and Colette Ricort for helpful technical assistance. The authors acknowledge the MARS beamline of SOLEIL synchrotron (Gif sur Yvette, France) that was used to perform XAS experiments and the IRCAN's Molecular and Cellular Core Imaging (PICMI) Facility which is supported by grants from the Ministère de l'Enseignement Supérieur, the Région PACA, the Conseil Départemental des Alpes Maritimes, INSERM, the FEDER, the GIS IBiSA, the Canceropole PACA and the foundation ARC. The author's lab work was funded by Université Côte d'Azur (UCA) and grants from the CEA ("Programme Transversal de Toxicologie Nucléaire") and the ANR (ANR-16CE34-0003-01). CCMA electron microscopy equipments have been funded by the Région Sud PACA, the Conseil Départemental des Alpes Maritimes and the GIS-IBiSA.

\section{Conflicts of interest}

The authors declare that they have no conflict of interest.

\section{Availability of data and material}

All data generated or analyzed during this study are included in this published article [and its supplementary information files] or are available from the corresponding author on reasonable request.

\section{Code availability}

Not Applicable 


\section{Introduction}

Natural uranium is a radioactive heavy metal widely used in various civil and military applications, which raises a problem of environmental pollution. In most environmental systems, natural uranium is found as the uranyl ion $\mathrm{UO}_{2}{ }^{2+}$ in the oxidation state $+\mathrm{VI}$ [referred as $\mathrm{U}(\mathrm{VI})$ hereafter]. Natural uranium-specific radioactivity being low, its toxic effects are mostly due to chemical damages to target organs, mainly the kidney and the skeleton (ATSDR 2013). In the skeleton, U(VI) accumulates in a dose- and time-dependent manner (Arruda-Neto et al. 2004; Larivière et al. 2013) and can be retained for several years (Leggett 1994; ATSDR 2013). The affinity of uranium for phosphate, one of the two main constituents of bone mineral, has been proposed to explain this behavior (Neuman and Neuman 1949). Since then, several studies have been conducted to examine the distribution of $\mathrm{U}(\mathrm{VI})$ in bone samples and have shown that this metal is rapidly fixed onto bone surfaces, preferentially on those undergoing active mineralization (Priest et al. 1982; Rodrigues et al. 2013; Bourgeois et al. 2015) and become buried with time by the apposition of new bone (Ellender et al. 1995; Bourgeois et al. 2015). However, to date, no mechanism explaining the biomineralization of $U(V I)$ is formally accepted. This is probably related to the complexity of the bone matrix and the different types of chemical interactions that can occur between uranyl cations and the different mineral and organic components of the bone matrix (Vidaud et al. 2012).

Acute or chronic exposure to $\mathrm{U}(\mathrm{VI})$ has been reported to affect bone formation in animal models (Guglielmotti et al. 1984; Guglielmotti et al. 1985; Ubios et al. 1991; Díaz Sylvester et al. 2002; Bozal et al. 2005; Wade-Gueye et al. 2012). Consistent with this observation, in vitro investigations have shown that $\mathrm{U}(\mathrm{VI})$ affects the viability and the function of both osteoblasts and osteocytes, which are the cells in charge of bone construction and bone 
remodeling regulation, respectively (Tasat et al. 2007; Milgram et al. 2008; Pierrefite-Carle et al. 2016; Hurault et al. 2019). Interestingly, $\mathrm{U}(\mathrm{VI})$ could exert its toxicity in both osteoblasts and osteocytes by altering the autophagic pathway, a major catabolic process (Pierrefite-Carle et al. 2016; Hurault et al. 2019).

The third type of bone cells crucial for bone remodeling is the osteoclast, which is responsible for bone resorption. Osteoclasts are large multinucleated cells resulting from the fusion of hematopoietic precursors and are able to solubilize both the mineral and organic components of the bone matrix. Autoradiographic and radiological analyses of bones isolated from rats injected with uranium, led to the proposal that resorption contributes to the distribution of uranium in the skeleton (Priest et al. 1982). Uranium could be resorbed from the bone surface, returned to the bloodstream and partially re-deposited in bone. A few studies then examined the effect of $\mathrm{U}(\mathrm{VI})$ on bone resorption in vivo (Ubios et al. 1991; Bozal et al. 2005; Fukuda et al. 2006). Ubios et al (1991) observed an increase in bone resorption by histomorphometric analysis of periodontal cortical bone in Wistar rats 14 days after intraperitoneal injection of uranyl nitrate. In mice given a lethal oral dose of uranyl nitrate, histomorphometric measurements of metaphyseal bone also revealed an extension of resorption surfaces compared to untreated animals (Bozal et al., 2005). On the other hand, no significant modification of metaphyseal bone resorption was observed after intramuscular injection of depleted uranium in rats in a later study (Fukuda et al. 2006). In addition to these animal studies using different models, uranium doses, and routes of administration, making the comparison difficult, an epidemiological investigation has addressed the question of the effects on bone health of uranium naturally present in drinking water. The authors provided evidence of a positive association (only in men) between uranium exposure and serum levels of the carboxy-terminal telopeptide, an indicator of bone resorption. Taken together, these in vivo studies led to the proposal that 
uranium might promote resorption. At the cellular level, we have recently demonstrated that $5 \mu \mathrm{M}$ of uranyl ion $\left(\mathrm{UO}_{2}{ }^{2+}\right)$ in solution is sufficient to strongly inhibit osteoclastic resorption due to an impairment of osteoclast formation and survival (Gritsaenko et al. 2017). To better understand the mechanism underlying the apparent discrepancy between the in vivo and in vitro effect of $\mathrm{U}(\mathrm{VI})$ on resorption and to mimic the physiological bone environment, we decided to examine the effect of $\mathrm{U}(\mathrm{VI})$ immobilized in bone-like matrices on the behavior and function of osteoclasts. As biomimetic material, we used a synthetic hydroxyapatite matrix as well as a "biological" matrix synthesized by an osteoblastic cell line in vitro. Using both biological and chemical approaches, these two supports were characterized and used to further analyze the effect of $\mathrm{U}(\mathrm{VI})$ on osteoclast function and to determine whether osteoclasts are able to remobilize the uranium trapped in the matrix via resorption, which has never been formally demonstrated. 


\section{Materials and Methods}

\section{Uranium exposure}

The stock solution of natural uranium (isotopic composition $99.27 \%{ }^{238} \mathrm{U}, 0.72 \%{ }^{235} \mathrm{U}$, and $\left.0.006 \%{ }^{234} \mathrm{U}\right)(100 \mathrm{mM}, \mathrm{pH} 4)$ was obtained by dissolving $85 \mathrm{mg}$ of uranyl acetate $\left(\mathrm{UO}_{2}\left(\mathrm{OCOCH}_{3}\right)_{2}, 2 \mathrm{H}_{2} \mathrm{O} ; \mathrm{M}=424 \mathrm{~g} \cdot \mathrm{mol}-1\right)$ in $2 \mathrm{ml}$ of distilled water. This stock solution was used to prepare extemporaneously working solutions, under conditions to control uranium speciation in the cell culture media of exposure, as previously described (Gritsaenko et al. 2017, 2018).

\section{Cell culture}

The Saos-2 cell line and the mouse monocyte/macrophage cell line RAW 264.7 were purchased from the American Type Culture Collection. Saos-2 cells were cultured as described by Lutter et al. (2010) with some modifications. Briefly, Saos-2 cells were maintained in McCoy's 5A medium without phenol red (HyClone, Thermo Fisher Scientific) supplemented with 15\% heat-inactivated fetal bovine serum (Biowest) and antibiotics (100 $\mathrm{IU} / \mathrm{mL}$ penicillin, $100 \mu \mathrm{g} / \mathrm{mL}$ streptomycin, Sigma-Aldrich). RAW 264.7 cells were maintained in Dulbecco's modified Eagle medium (DMEM, Lonza) supplemented with 5\% HyClone serum (HyClone, Thermo Fisher Scientific) and antibiotics (100 IU/ml penicillin and $100 \mu \mathrm{g} / \mathrm{ml}$ streptomycin). Cells were grown in $75 \mathrm{~cm}^{2}$ flasks and passed by mechanical scraping.

\section{Biomimetic matrices}

24-well Osteo assay plates that provide a synthetic inorganic bone mimetic surface (Corning Life Science) were incubated at $37^{\circ} \mathrm{C}$ with aMEM medium $(1 \mathrm{ml} /$ well) containing 
the indicated concentration of $\mathrm{U}(\mathrm{VI})$. After 48 hours, the medium was discarded and the plates were used directly either for $\mathrm{U}(\mathrm{VI})$ quantification or for osteoclastic differentiation and resorption assays.

For matrix production, 20,000 Saos-2 cells/well of complete McCoy's 5A medium were seeded in 24-well culture plates. When the confluence reached $90 \%$, growth medium was replaced by differentiation medium ( $\alpha$-MEM, 10\% heat-inactivated FBS, $300 \mu \mathrm{M}$ ascorbic acid, $10 \mathrm{mM} \beta$-glycerol phosphate) containing either $0,0.5,1$ or $2 \mu \mathrm{M} \mathrm{U}(\mathrm{VI})$. Culture medium without or with $\mathrm{U}(\mathrm{VI})$ was changed on days 3,5 and 7 of culture. On day 10 , the resulting matrices were de-cellularized with $20 \mathrm{mM} \mathrm{NH} 4 \mathrm{OH}$ for $10 \mathrm{~min}$. at room temperature, then treated with DNase I ( $1 \mathrm{mg} / \mathrm{ml}$ in $\alpha-M E M)$ for $15 \mathrm{~min}$. at $37^{\circ} \mathrm{C}$, rinsed in $\alpha$ MEM medium and immediately used either for $\mathrm{U}(\mathrm{VI})$ quantification or for osteoclastic differentiation and resorption assays.

\section{Mineralization assay}

The Saos- 2 cells were seeded in 24 -well plates at a density of 20.000 cells/well. When subconfluence was reached. the growth medium was replaced with differentiation medium containing either 0.0 .5 . 1 or $2 \mu \mathrm{MU}(\mathrm{VI})$ and the culture was maintained for 10 days with a change of medium every $2-3$ days.

For mineralization evaluation, cultures were fixed with $4 \%$ formaldehyde solution (Sigma-Aldrich), rinsed with deionized water and stained with $1 \%$ Alizarin Red S solution (Alfa Aesar. ThermoFisher Scientific) for $5 \mathrm{~min}$. Intensive washes with deionised water were then carried out before the plates were left to dry and photographed. Images of each well were analyzed with ImageJ software to evaluate the percentage of mineralized area. 


\section{Osteoclast generation, TRAP staining and pit resorption assays}

Osteoclastic differentiation and resorption were analyzed as previously described (Gritsaenko et al. 2017, 2018) with minor modifications. Briefly, RAW 264.7 pre-osteoclastic cells were seeded at a density of 5000 cells $/ \mathrm{cm}^{2}$ on synthetic apatite matrices (osteo assay plates) and a density of 20,000 cells $/ \mathrm{cm}^{2}$ on matrices produced by Saos-2 cells, in the following differentiation medium: alpha modified Minimum Essential Medium (aMEM, Lonza) with $2 \mathrm{mM} \mathrm{L-Glutamine} \mathrm{(Sigma-Aldrich),} \mathrm{5 \%} \mathrm{HyClone} \mathrm{fetal} \mathrm{bovine} \mathrm{serum,} 100 \mathrm{IU} / \mathrm{mL}$ penicillin, $100 \mu \mathrm{g} / \mathrm{mL}$ streptomycin (Sigma-Aldrich) and $50 \mathrm{ng} / \mathrm{ml}$ of the recombinant cytokine GST-RANKL. The medium was changed on day 3.

To analyse osteoclastogenesis, cells obtained on day 4 (for cells cultured on synthetic apatite matrice) or on day 5 (for cells cultured on Saos-2 matrices) were fixed for $2 \mathrm{~min}$ at room regutemperature with $3 \%$ formaldehyde and $66 \%$ acetone in $7 \mathrm{mM}$ citrate solution and subjected to Tartrate-resistant acid phosphatase (TRAP) staining using Leukocyte acid phosphatase kit as described by the manufacturer (Sigma-Aldrich).

To analyse resorption, osteoclasts obtained after 4 or 5 days were removed from the bone mimetic surface by incubation with $10 \%$ bleach for $5 \mathrm{~min}$ at room temperature. After two washes in water, plates were incubated 2 min with an Alizarin Red $\mathrm{S}$ sodium salt $1 \%$ solution (Alfa Aesar), which stains calcium salts, and washed again in water. In order to evaluate the percentage of resorbed area, images of each well were analyzed with ImageJ software. The resorbed surface fraction was then measured using the "limit to threshold" algorithm. The number of experimental replicates and the number of independent experiments performed are provided in the figure legends.

\section{Scanning electron microscopy and EDX analysis}


For scanning electron microscopy (SEM) and energy-dispersive X-ray spectroscopy (EDX), cellularized samples were fixed in a $1.6 \%$ glutaraldehyde solution in $0.1 \mathrm{M}$ sodium phosphate buffer $(\mathrm{pH} 7.4)$ at room temperature for 1 hour and then stored at $4^{\circ} \mathrm{C}$. After being rinsed three times with distilled water, samples were dehydrated in a series of ethanol baths $(70 \%, 96 \%, 100 \%$ three times, $15 \mathrm{~min}$ each). Samples were then incubated 5 minutes in hexamethyldisilazane (HMDS) and left to dried overnight. Decellularized samples were left to dry. Samples were then mounted on SEM stubs with carbon tape and silver paint. For SEM imaging, samples were coated with platinum $(3 \mathrm{~nm})$ prior to observations with a Jeol JSM-6700F SEM at an accelerating voltage of $3 \mathrm{kV}$. For EDX analyses, sample were carbon coated and analyses were carried with a Tescan Vega3 XMU scanning electron microscope (TESCAN FRANCE) equipped with an Oxford X-MaxN 50 EDX detector (Oxford Instruments) with a $20 \mathrm{kV}$ accelerating voltage. EDX data were processed with the Aztec software (version 3.1, Oxford Instruments).

\section{Transmission Electron Microscopy and HRTEM-EDX spectroscopy}

Samples were fixed with $1.6 \%$ glutaraldehyde in $0.1 \mathrm{M}$ phosphate solution immediately after medium removal. Cells were rinsed with $0.1 \mathrm{M}$ cacodylate buffer and post-fixed for $1 \mathrm{~h}$ in the same buffer containing $1 \%$ osmium tetroxide. After rinsing with distilled water and progressive dehydration with increasing ethanol concentration solutions, cells were embedded in epoxy resin. Ultrathin sections $(70 \mathrm{~nm})$ were realized and put on Formvarcoated copper grids. Grids were stained or not with uranyl acetate and lead citrate before examination of sections with a Jeol JEM 1400 transmission electron microscope equipped with a SIS MORADA camera.

For high-resolution transmission electron microscopy (HRTEM), the unstained grids were coated with an additional $10 \mathrm{~nm}$-thick carbon coating performed with a turbo-pumped 
carbon evaporator (Balzers MDE010), for sample conductivity. Samples were analyzed on an HRTEM microscope (JEOL 2100F) with an acceleration voltage of $200 \mathrm{kV}$ and equipped with an energy dispersive X-ray (EDX) spectroscopy system. HRTEM images were digitally recorded with a Gatan Ultrascan 1000 camera (Gatan), with acquisition software Gatan Digital Micrograph. The analysis system was EDS-SDD Oxford X-Max (Oxford Instruments). Elements $\mathrm{P}, \mathrm{Ca}$ and $\mathrm{U}$ were quantified by using respectively $\mathrm{OK \alpha}, \mathrm{PK \alpha}, \mathrm{CaK \alpha}$ and ULa spectral lines of these elements, and by using a Cliff-Lorimer standardless quantification method with INCA software (Oxford Instruments).

\section{ICP-MS analysis}

Culture supernatants were acidified with nitric acid $\left(\mathrm{HNO}_{3}\right)$ and stored at $-20^{\circ} \mathrm{C}$ until ICPMS analysis. Synthetic and biological matrices were dried at room temperature and rinsed 3 times using $65 \%$ concentrated $\mathrm{HNO}_{3}(3 \times 1 \mathrm{ml})$. Each solution was evaporated to dryness on a hotplate after being heated to $120^{\circ} \mathrm{C}$ during $3-4 \mathrm{~h}$ and re-dissolved into a $\mathrm{HNO}_{3}$ solution at $\mathrm{pH} 1 \%$. After appropriate dilution in $\mathrm{HNO} 31 \%$, samples were injected via a peristaltic pump equipped with Tygon tubing at $400 \mu \mathrm{L} / \mathrm{min}$ flow rate and nebulized by means of a micro-concentric nebulizer. Quantification was performed by inductively coupled plasma mass spectrometry (ICP-MS; 7700, Agilent Technologies) at $\mathrm{m} / \mathrm{z}=238$. ICP conditions were the following: nebulization gas flow rate: $1 \mathrm{~L}$ min-1, dilution gas flow rate: $0.1 \mathrm{~L} / \mathrm{min}$, plasma gas flow rate: $15 \mathrm{~L} / \mathrm{min}$, auxiliary gas flow rate: $1 \mathrm{~L} / \mathrm{min}$. Plasma power was set to $1550 \mathrm{~W}$. Other parameters were adjusted to both maximize the analyte signal and minimize oxide and doubly charged ions formation. The standard curve (0.4 to 40 $\mathrm{nmol} / \mathrm{L}$ of $\mathrm{U}$ ) was prepared from the PlasmaCAL standard (U $1000 \mu \mathrm{g} / \mathrm{mL}$, SCPscience). The detection limit calculated by the MassHunter software was $0.01 \mathrm{nmol} / \mathrm{L}$. Each sample was measured in triplicate. Between analyses, the system was rinsed for $30 \mathrm{~s}$ min with 
HNO3 $1 \%$ and $30 \mathrm{~s}$ with ultrapure water and a blank (HNO3 1\%) was injected to control the absence of any memory effect.

\section{Extended X-Ray Absorption Fine Structure Analysis}

Samples for EXAFS data acquisition were prepared as solid pellets made from a mixing of

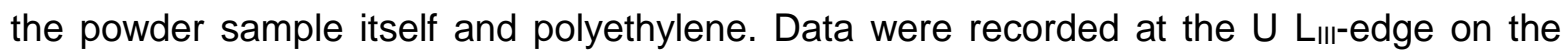
MARS beam line at the SOLEIL synchrotron facility $(2.75 \mathrm{GeV} ; 400 \mathrm{~mA})$, which is the French bending magnet beamline dedicated to the study of radioactive materials (Sitaud et al. 2012). All the measurements were recorded in fluorescence mode using a 13-element high purity germanium solid-state detector. EXAFS data were processed with the Athena code and fitted in R space with the Artemis code of Demeter package 0.9.25 (Ravel and Newville 2005). In all the fits, only one global amplitude factor $S_{0}{ }^{2}$ and one energy threshold $\mathrm{e}_{0}$ factor were considered for all the scattering contributions. Hanning windows with $\mathrm{k}^{2}$ weight $\left[2.5 ; 11.5 \AA^{-1}\right]$ and fitting range in $R$ space $[1.0 ; 5.0 \AA]$ were selected. Phases and amplitudes were calculated with Feff7 code included in Artemis (Rehr et al. 2010) using the crystal structure of autunite $\mathrm{Ca}\left[\left(\mathrm{UO}_{2}\right)\left(\mathrm{PO}_{4}\right)\right]_{2}\left(\mathrm{H}_{2} \mathrm{O}\right)_{11}$ (Locock and Burns 2003). The first two single scattering paths correspond to the 2 axial oxygen atoms $\mathrm{O}_{a x}$ and to the equatorial oxygen atoms $\mathrm{O}_{\text {eq. }}$. Additional single scattering path corresponding to phosphorous (U...P) was also added. Several multiple scattering paths were also needed: quadruple path involving axial oxygen atoms $\left(\cup \ldots \mathrm{O}_{\mathrm{ax}} \ldots \cup \ldots \mathrm{O}_{\mathrm{ax}}\right)$, and triple path involving equatorial oxygens of phosphates $\left(U \ldots . . . O_{e q}\right)$. During the fit procedure, the number of axial oxygen atoms was fixed to 2 for the $\mathrm{UO}_{2}{ }^{2+}$ oxocation. The agreement factor (in \%) and reduced quality factor $\mathrm{X}^{2}{ }^{2} \mathrm{n}$ of the fit are both provided as an indication of fit quality in the $\mathrm{R}$ space.

\section{Statistical analysis}




\begin{abstract}
Statistical analyses were performed with Prism 7.00 (GraphPad Software). Due to the size of the samples we used non-parametric approaches. Data were submitted, as indicated, to two-sided Mann-Whitney test or two-way analysis of variance (ANOVA) with the two-stage step-up method of Benjamini, Krieger and Yekutieli to control the false discovery rate.
\end{abstract}




\section{Results}

\section{The synthetic apatite matrix model}

The first model used as mineralized matrices containing uranium, was a commercially available synthetic surface made of an inorganic crystalline calcium phosphate (COAS for Corning Osteo-Assay Surface) (Faruqi et al. 2011) that is usually used to assess osteoclast and osteoblast activity in vitro (Gigliotti et al. 2016; Gritsaenko et al. 2017, 2018). The plates were incubated with $\alpha$-MEM medium containing uranyl acetate concentrations ranging from 0 to $100 \mu \mathrm{M}$. After a $48 \mathrm{~h}$ incubation period, the amount of $\mathrm{U}(\mathrm{VI})$ retained on the synthetic surface was measured by ICP-MS (Fig. 1a). We observed that $\mathrm{U}(\mathrm{VI})$ was successfully retained on the calcium phosphate layer in a non-linear dose-dependent manner, reaching levels of $\mathrm{U}(\mathrm{VI})$ up to $1.4 \mu \mathrm{g} /$ well for matrices incubated with $100 \mu \mathrm{M} \mathrm{U}(\mathrm{VI})$ in solution.

The speciation of uranium within the inorganic calcium phosphate phase was compared to its speciation in a pure autunite sample $\left[\mathrm{Ca}\left(\mathrm{UO}_{2}\right)_{2}\left(\mathrm{PO}_{4}\right)_{2}\left(\mathrm{H}_{2} \mathrm{O}\right)_{11}\right]$. Among uranyl phosphates, autunite is the most stable form and it is also very similar to the uranyl phosphate phase identified into osteoblastic and osteocytic cells exposed to uranium (Pierrefite-Carle et al. 2016; Hurault et al. 2019). The EXAFS spectrum of synthetic matrices exposed to a solution of $100 \mu \mathrm{M} \mathrm{U}(\mathrm{VI})$ for $48 \mathrm{~h}$ was recorded at the $\mathrm{U} \mathrm{L}_{\text {III }}$ edge and compared with the EXAFS spectrum of autunite. The EXAFS experimental spectra and corresponding Fourier transforms are shown in Fig. 1b and the best parameters of the fit are presented in Supplementary Table 1. In short, in the synthetic COAS matrix, the uranyl equatorial plane consists of $5.5 \pm 0.6 \mathrm{O}_{\text {eq }}$ at $2.40 \pm 0.3 \AA$ and $4.2 \pm 1.0 \mathrm{P}$ at $3.65 \pm 0.4 \AA$ compared to $4.1 \pm 1.0 \mathrm{O}_{\text {eq }}$ at $2.33 \pm 0.5 \AA$ and $5.7 \pm 1.2 \mathrm{P}$ at $3.59 \pm 0.5 \AA$ in the case of pure autunite [crystallographic data for pure autunite phase are: $4 \mathrm{O}_{\text {eq }}$ at $2.28 \AA$ and $4 \mathrm{P}$ at 3.60 


\begin{abstract}
$\AA$ (Locock and Burns 2003)]. In both cases, phosphate contributions at about the same distance were needed for the fit. Nonetheless, the $\mathrm{U}-\mathrm{O}_{\text {eq }}$ distances in the synthetic matrix $(2.40 \pm 3 \AA)$ are slightly longer than distances in the autunite phase obtained from EXAFS (2.33 $\pm 0.5 \AA$, this work) and significantly longer than the distances in pure autunite as determined by X-ray crystallography (mean $2.28 \AA$ ) (Locock and Burns 2003). Altogether, these data suggest that $U(V I)$ in the inorganic COAS matrix exists as a phosphate phase, with probably a more disordered equatorial plane than in the pure autunite phase (larger equatorial coordination number and equatorial distance).
\end{abstract}

\title{
$\mathrm{U}(\mathrm{VI})$ and osteoclast behavior on synthetic matrices
}

$\mathrm{U}(\mathrm{VI})$-loaded synthetic matrices were used as cell culture support and substrate for osteoclastic resorption to investigate both the fate of $\mathrm{U}(\mathrm{VI})$ under different culture conditions and the effect of $\mathrm{U}(\mathrm{VI})$ on osteoclastic resorption. To this end, we prepared several sets of synthetic matrices exposed to increasing concentrations of $U(V I)(0,5,10,25,50$ and 100 $\mu \mathrm{M})$. Set of matrices with resulting amounts of adsorbed $U(\mathrm{VI})$ ranging from 0 to about $1 \mu \mathrm{g}$ per well, were selected, seeded with RAW 264.7 pre-osteoclastic cells and maintained in culture during 4 days with a change of medium performed at the beginning of day 3 (D3) (Fig. 2a). The cell cultures were carried out in the absence (RANKL-) or the presence of the RANKL (RANKL+) cytokine, which is necessary to induce osteoclastic differentiation of precursor cells. It is important to note that, the majority of the osteoclastic resorption occurs between culture days 3 and 4 in RANKL+ conditions, i.e. after the culture medium change. As shown in Supplementary Fig. 1, osteoclasts, defined as cells having more than 3 nuclei and positive for tartrate-resistant acid phosphatase (TRAP) activity staining, were observed in the presence of RANKL in all tested conditions. To assess whether $\mathrm{U}(\mathrm{VI})$ could be 
remobilized in the culture medium by osteoclastic resorption, we then evaluated by ICP-MS the amounts of $\mathrm{U}(\mathrm{VI})$ in culture supernatants on days 3 and 4 as well as in matrices at the end of culture on day 4. As shown in Fig. $2 b$ a large part of $U(V I), 49$ to $70 \%$ depending on the conditions, was found into the culture medium collected at day 3 (D3 supernatants). This was observed in either RANKL- or RANKL+ culture conditions, indicating that U(VI) adsorbed on synthetic apatite was massively and passively released into the medium during this culture period. Over the next 24 hours, 6 to $7.5 \% \mathrm{U}(\mathrm{VI})$ were measured in the culture medium (D4 supernatants) under RANKL- conditions, while this percentage was higher (9 to 13\%) under almost all RANKL+ conditions (Fig. 2b). Statistical analysis of the amounts of $\mathrm{U}(\mathrm{VI})$ present in D4 supernatants (Fig. 2c) showed significant differences between RANKL+ and RANKL- supernatants. These findings suggested that $U(V I)$ adsorbed on synthetic apatite matrices may be remobilized by osteoclastic resorption. This was confirmed by $\mathrm{U}(\mathrm{VI})$ quantification in final matrices, showing that all matrices maintained under RANKL+ conditions contained less $\mathrm{U}(\mathrm{VI})$ than those cultured without RANKL (Fig. 2d). This trend observed for all $\mathrm{U}(\mathrm{VI})$-loaded matrices became significant for those initially containing the highest amount of $\mathrm{U}(\mathrm{VI})(0.75$ and $1 \mu \mathrm{g})$ (Fig. $2 \mathrm{~d})$.

We next assessed the resorption efficiency of the synthetic matrices as a function of their $\mathrm{U}(\mathrm{VI})$ content. Matrices containing the highest amounts of $\mathrm{U}(\mathrm{VI})(0.45,0.75$ and $1 \mu \mathrm{g})$ showed similar resorption efficiency to matrices without $\mathrm{U}(\mathrm{VI})$ (Fig. 3a). In contrast, we observed significant stimulation of osteoclastic resorption for matrices containing an average of 0.16 and $0.24 \mu \mathrm{g} \mathrm{U}(\mathrm{VI})$, respectively (Fig. 3a). To attempt to understand these effects of $\mathrm{U}(\mathrm{VI})$ on resorption, the presence of $\mathrm{U}(\mathrm{VI})$ in the matrix but also in solution must be considered. Indeed, due to the passive release of $U(V I)$ by the synthetic apatite, the concentrations of $\mathrm{U}(\mathrm{VI})$ in the culture medium reach significant levels that we have calculated and reported in Supplementary Table 2. Therefore, it cannot be excluded that 
the observed effects on resorption are due to uranium in solution. In an attempt to clarify this issue, the direct effect of $\mathrm{U}(\mathrm{VI})$ in solution was evaluated by testing concentrations close to those found in the culture supernatants of the synthetic matrices. RAW 264.7 cells were seeded on synthetic matrices with $\mathrm{U}(\mathrm{VI})$ concentrations ranging from 0 to $5 \mu \mathrm{M}$ in the culture medium and in the presence of RANKL. We observed that 0.25 and $0.5 \mu \mathrm{M} U(\mathrm{VI})$ in the culture medium significantly increased resorption (Fig. 3b), suggesting that the resorption stimulation observed with matrices containing 0.16 and $0.24 \mu \mathrm{U}(\mathrm{VI})$ may be due to $\mathrm{U}(\mathrm{VI})$ release in the culture medium. In agreement with this hypothesis, we found that concentrations of $\mathrm{U}(\mathrm{VI})(1$ and $3 \mu \mathrm{M})$, close to those found in the culture supernatants of the matrices with no effect on resorption (matrices containing 0.45 to $1 \mu \mathrm{g} U(\mathrm{VI})$, Fig. 3a), had themselves no effect on osteoclastic function (Fig. 3b). Finally, we also replicated our previously reported results (Gritsaenko et al. 2017) showing that $5 \mu \mathrm{M} \mathrm{U}(\mathrm{VI})$ significantly inhibits resorption.

Taken together, our experiments demonstrate for the first time that osteoclast resorption is capable of remobilizing $\mathrm{U}(\mathrm{VI})$ adsorbed on an apatite layer matrix and that low concentrations of remobilized $\mathrm{U}(\mathrm{VI})$ may promote osteoclast resorption function. These results also pointed out that $\mathrm{U}(\mathrm{VI})$ can have opposite effects on osteoclastic function depending on its concentration.

\section{The biological Saos-2 matrix model}

To get closer to physiological conditions, a second model was developed in the form of extracellular matrices synthesized by an osteoblastic cell line (Saos-2) cultured in the presence of low concentrations of $\mathrm{U}(\mathrm{VI})$. Alizarin red staining of the resulting matrices revealed a decrease in mineralization in the presence of uranium [ $\approx 29 \%$ at $2 \mu \mathrm{M} \mathrm{U}(\mathrm{VI})]$ (Fig. 4a), a result already observed for other types of osteoblastic cells (Pierrefite-Carle et 
al. 2016; Hurault et al. 2019). SEM analyses showed that Saos-2 cells produces a thin matrix with globular structures distributed on it, an architecture that was apparently not disturbed by the presence of $2 \mu \mathrm{M} U(\mathrm{VI})$ during the synthesis phase (Fig. 4b). Energy dispersive X-ray (EDX) experiments further established that these globular structures correspond to calcium phosphate deposits (Fig. 4c). Moreover, transmission electron microscopy showed the presence under both conditions ( 0 and $2 \mu \mathrm{M})$ of collagen fibrils recognizable by their band patterning (Fig. 4d). These results indicated that Saos-2 cells were able to produce an organic and mineralized extracellular matrix in the presence or absence of $2 \mu \mathrm{MU}(\mathrm{VI})$. The ultrastructure of these matrices did not appear to be affected by the presence of $2 \mu \mathrm{MU}(\mathrm{VI})$, contrary to the level of mineralization, which is noticeably reduced under these conditions.

Although $\mathrm{U}(\mathrm{VI})$ could not be detected by EDX in Saos-2 matrices (Fig. 4c) ICP-MS assays showed that up to $1 \mu \mathrm{g} U(\mathrm{VI})$ can be incorporated into a matrix synthesized by Saos-2 (Fig. 4 e). This incorporation was highly reproducible and increased linearly with the amount of $\mathrm{U}(\mathrm{VI})$ present in the culture medium during matrix synthesis. The EXAFS analyses of biological matrix synthetized in the presence of $2 \mu \mathrm{M} U(\mathrm{VI})$ were also performed. The resulting EXAFS spectrum (Fig. 4f) and its fit (Supplementary Table 1) demonstrate the presence of a uranyl phosphate phase. The U-Oeq distances in biological Saos-2-matrices $(2.34 \pm 0.1 \AA)$ are closer to those of pure autunite as established by EXAFS $(2.33 \pm 0.5 \AA)$ or X-ray crystallography (mean 2.28) (Locock and Burns 2003), than the distances in synthetic COAS-matrices $(2.40 \pm 0.3)$. Although these differences are at the limit of the uncertainties (see Supplementary Table 1), they suggested that the local arrangement around uranium is different in the two types of matrices. This could be explained by a more organized uranyl phosphate phase in the case of biological matrices. 


\section{$\mathrm{U}(\mathrm{VI})$ and osteoclast behavior on biological matrices}

Biological matrices prepared from Saos-2 cell culture were decellularized and used as a support for RAW 264.7 cells osteoclastic differentiation according to the protocol presented in Fig. 2a. We first evaluated the distribution of $\mathrm{U}(\mathrm{VI})$ and noticed that, as in the case of synthetic matrices, the presence of RANKL appeared to be associated with an increase in $\mathrm{U}(\mathrm{VI})$ release (Fig. 5a). This was confirmed by statistical analysis of the quantities of $U(\mathrm{VI})$ present in D5 supernatants (Fig. 5b). In the presence of RANKL, D3 supernatants also contained more $\mathrm{U}(\mathrm{VI})$ compared to control samples, although this difference did not reach significance (Fig. 5b). Likewise, the presence of RANKL in the culture medium resulted in a very small and not statistically significant effect on the amount of $\mathrm{U}(\mathrm{VI})$ present in the final Saos-2 matrices, detected in the case of the matrices with the lowest initial $\mathrm{U}(\mathrm{VI})$ content (0.28 and $0.54 \mu \mathrm{g} U(\mathrm{VI}) /$ well) (Fig. 5c).Taken together, these data suggested that part of the $\mathrm{U}(\mathrm{VI})$ incorporated in mineralized extracellular biological matrices could be released into the culture medium via osteoclastic resorption, as shown by using the synthetic matrix model.

After checking the formation of osteoclasts on biological matrices (Supplementary Figure 2), we used them to analyze osteoclastic function. We found a low resorption level (Fig. 5d) compared to the one obtained on synthetic matrices (Fig. 3a) and a high inter and intraexperimental variability. In addition, none of the conditions tested led to a significant change in resorption efficiency.

\section{$\mathrm{U}(\mathrm{VI})$ detection inside vesicles of resorbing osteoclasts}

Using transmission electron microscopy, we then analyzed osteoclasts that have resorbed biological matrices containing either 0 or $1 \mu \mathrm{g} U(\mathrm{VI})$. In $100 \%$ of osteoclasts formed on matrices with $\mathrm{U}(\mathrm{VI})$ that we have examined, we noticed one (Fig. 6a) or several large 
vesicles (Supplementary Fig. 3a) containing both isolated needle- or platelet-shaped structures with irregular edges, the latter being very similar to bone apatite crystals both in size and morphology (Kim et al. 1995; Su et al. 2003). No equivalent observations were made when we examined osteoclasts formed on matrices without $\mathrm{U}(\mathrm{VI})$. In addition, vesicles with the same content have not been observed on osteoclasts formed on synthetic matrices containing or not $\mathrm{U}(\mathrm{VI})$. To determine the composition of these intra-vesicular structures, high-resolution TEM - Energy-dispersive X-ray spectroscopy (HRTEM-EDX) was used and showed that both needles and platelets were of composed uranium and phosphorus without a detectable level of calcium in the vast majority of cases (Fig. $6 \mathrm{~b}$ and Supplementary Fig. 3b), suggesting that both of them would actually correspond to the same structures positioned differently with respect to the section plane.

In conclusion, these data suggested that $\mathrm{U}(\mathrm{VI})$ incorporated into biological matrices can accumulate in resorbing osteoclasts as uranyl phosphate crystal-like structures, within vesicles whose nature and function remains to be determined. 


\section{Discussion}

In order to improve our understanding of the effects of $\mathrm{U}(\mathrm{VI})$ on osteoclastic resorption and the consequences of resorption on $\mathrm{U}(\mathrm{VI})$-distribution into the skeleton, we developed bone biomimetic matrices containing different amounts of $\mathrm{U}(\mathrm{VI})$ and used then as support and substrate for respectively in vitro osteoclastic differentiation and resorption. We first obtained synthetic biomimetic matrices containing 0.16 to $1.7 \mu \mathrm{g} U(\mathrm{VI})$ as determined by ICP-MS. EXAFS analyses further showed that the main speciation of uranium in these bone-like surfaces is a uranyl phosphate phase but apparently less condensed than in the pure autunite phase. We found that up to $70 \%$ of $\mathrm{U}(\mathrm{VI})$ incorporated in these synthetic matrices could be passively released into the medium after three days of culture. Although the mechanisms of immobilization of $\mathrm{U}(\mathrm{VI})$ on apatite have been intensively studied (Bostick et al. 1999; Fuller et al. 2002, 2003; Thakur et al. 2009) they are not fully understood most likely because they depend on a wide range of parameters such as $\mathrm{U}(\mathrm{VI})$ speciation, concentration, $\mathrm{pH}$ and temperature (Thakur et al. 2009; Mehta et al. 2016). The mechanisms governing $\mathrm{U}(\mathrm{VI})$ uptake and the exchanges between the solid and liquid phases in our culture conditions remain to be clarified. However, we considered these synthetic matrices to be relevant for our experiments because they contain $\mathrm{U}(\mathrm{VI})$ in a form previously detected inside osteoblasts and osteocytes (Pierrefite-Carle et al. 2016; Hurault et al. 2019) and which is quantifiable by ICP-MS both in the matrix and in culture supernatants, allowing its distribution to be monitored.

To better mimic bone matrix and because interaction between $\mathrm{U}(\mathrm{VI})$ and the organic part of the bone matrix is important for $\mathrm{U}(\mathrm{VI})$ incorporation (Basset et al. 2013; Qi et al. 2014; Huynh et al. 2016), we also used biological matrices synthesized in vitro by Saos-2 
osteoblastic cells. In our experimental conditions, Saos-2 cells produced a matrix combining mineral and organic phases, as expected (Lutter et al. 2010), and enclosing a maximum of $1 \mu \mathrm{g}$ of $\mathrm{U}(\mathrm{VI})$. We found that no more than 2 to $4 \%$ of $\mathrm{U}(\mathrm{VI})$ contained in the initial matrix was passively released after 3 days of culture, compared to $70 \%$ in the case of synthetic surfaces. This difference in $\mathrm{U}(\mathrm{VI})$ behavior could be explained by a tighter interaction of $\mathrm{U}(\mathrm{VI})$ with biological matrices than synthetic ones. Indeed, we hypothesize that $\mathrm{U}(\mathrm{VI})$ is biomineralized and incorporated in biological matrices while it is simply adsorbed on the surface of the synthetic apatite. This hypothesis is strengthened by EXAFS data, which suggest that coordination around $\mathrm{U}(\mathrm{VI})$ is distinct in both types of matrices with a more organized arrangement in the case of biological matrices, as supported by shorter U-Oeq distances (2.34 $\pm 0.1 \AA ̊$ compared to $2.40 \pm 0.3 \AA$ in the case of COAS synthetic matrices). Interestingly, Mehta et al. (Mehta et al. 2016) found shorter bond lengths between uranium and equatorial oxygens in samples prepared by combining $\mathrm{U}(\mathrm{VI})$, calcium, and phosphate simultaneously (a situation comparable to that of our experiments with biological matrices) than in those obtained by adding $\mathrm{U}(\mathrm{VI})$ to pre-formed apatite (a situation similar to that of our experiments with synthetic matrices). In agreement with our hypothesis, the authors proposed that these differences in $\mathrm{U}(\mathrm{VI})$ environment reflect the distinct $\mathrm{U}(\mathrm{VI})$ uptake mechanisms occurring in the two situations: incorporation of $\mathrm{U}(\mathrm{VI})$ into the calcium phosphate in the first case versus adsorption onto pre-formed apatite in the second case. In addition, although our EXAFS data suggest that $\mathrm{U}(\mathrm{VI})$ is mainly present as a mineral autunite-like phase in Saos-2-synthesized matrices, it cannot be excluded that part of U(VI) is complexed with matrix proteins such as osteopontin which binds $\mathrm{U}(\mathrm{VI})$ with nanomolar affinity, or other non-collagenous SIBLING proteins which share features favorable to the binding of uranyl cations (Qi et al. 2014). 
The monitoring of $\mathrm{U}(\mathrm{VI})$ distribution during cell culture, also showed that the presence of resorbing cells (obtained when RAW 264.7 cells were cultured in the presence of RANKL) is associated with a significant increase in the release of $\mathrm{U}(\mathrm{VI})$ from matrices. This was observed for both synthetic and biological matrices. The results are significantly more robust in the case of synthetic apatite, certainly due to the important level of resorption obtained with these substrates. Indeed, by quantifying resorption, we observed that this process was more effective on synthetic matrices (up to $47 \%$ of the well surface) than on biological matrices (up to $13 \%$ of the well surface), regardless of the presence of uranium. This could be explained by the fact that synthetic matrices are made up of a very thin layer of very homogeneous apatite while biological ones are thicker and heterogeneous with an organic and mineral phase. However, taken together these results provide the first direct evidence that uranium can be remobilized via osteoclastic resorption.

We then sought to determine the influence of uranium on osteoclast activity. First, we found that resorption was significantly increased for synthetic matrices containing 0.16 or $0.24 \mu \mathrm{g}$ of $\mathrm{U}(\mathrm{VI})$. Due to the passive release of $\mathrm{U}(\mathrm{VI})$ from the synthetic apatite, the use of these matrices led to an accumulation of $\mathrm{U}(\mathrm{VI})$ in the culture medium which after three days of culture reached concentrations close to 0.3 and $0.6 \mu \mathrm{M}$, respectively. This prompted us to evaluate the direct effect of $\mathrm{U}(\mathrm{VI})$ in solution by testing concentrations close to those found in the culture supernatants of the synthetic matrices. In doing so, we observed that 0.25 and $0.5 \mu \mathrm{MU}(\mathrm{VI})$ in the culture medium induced significant stimulation of resorption. These data led us to propose that the stimulation of resorption observed using the synthetic matrices with 0.16 and $0.24 \mu \mathrm{g} U(\mathrm{VI})$ was in fact due to $\mathrm{U}(\mathrm{VI})$ released into the culture medium rather than $\mathrm{U}(\mathrm{VI})$ immobilized on the apatite. Resorption stimulation was not observed for Saos-2 matrices, even for those containing amounts of $\mathrm{U}(\mathrm{VI})$ comparable to 
those present in synthetic matrices with increased resorption $(0.28 \mu \mathrm{g}$ for biological matrices versus $0.24 \mu \mathrm{g}$ for synthetic matrices). This discrepancy could result from the different levels of $\mathrm{U}(\mathrm{VI})$ released in the culture medium depending on the type of matrices (almost 20 times more for synthetic matrices than for biological ones) and strengthens the hypothesis that the observed effects on resorption are mainly due to $\mathrm{U}(\mathrm{VI})$ present in the liquid phase.

More importantly, our findings indicate for the first time that $\mathrm{U}(\mathrm{VI})$ can exert opposite effects on osteoclast behavior as a function of its concentration: $5 \mu \mathrm{M} \mathrm{U}(\mathrm{VI})$ inhibits resorption as shown here and in our previous study (Gritsaenko et al. 2017), whereas $0.25 \mu \mathrm{M}$ promotes it, in our in vitro conditions. These data should be compared with those obtained in vivo, which suggest an increase in resorption after exposure to U(VI) (Ubios et al. 1991; Kurttio et al. 2005; Bozal et al. 2005; Fukuda et al. 2006). By decreasing the concentration of U(VI) in our experiments, we may have moved closer to realistic conditions. However, it must be stressed that the comparison remains complex, especially since uranium is not homogeneously distributed in bones and concentrates mainly in the remodeling areas (Priest et al. 1982; Ellender et al. 1995; Bourgeois et al. 2015). This raises the possibility that, in vivo, substantial concentrations of $\mathrm{U}(\mathrm{VI})$ may be reached in bone remodeling compartments, which are specialized structures providing a confined microenvironment involved in the local regulation of remodeling and where exchanges of organic and mineral matrix constituents are thought to take place (Hauge et al. 2001; Eriksen 2010). Our results also raise the question of molecular mechanisms involved in the opposite effects of $U(V I)$ on osteoclastic function. Analysis of the different stages of osteoclastic differentiation and resorption using the different methodologies and tools we have developed should clarify this point. 
During resorption, bone degradation products are internalized into osteoclasts at the level of their apical ruffled border, packaged into transcytosis vesicles and transported through the cell to a restricted area of the basolateral membrane (called the functional secretion domain), where they are secreted ( $\mathrm{Ng}$ et al. 2019). Transmission electron microscopy experiments revealed that osteoclasts that have resorbed biological matrices containing $\mathrm{U}(\mathrm{VI})$, have one or more vesicles up to several $\mu \mathrm{m}$ in size, in which needle and plateletshaped structures are homogeneously distributed. EDX spectroscopy further determined that these structures are formed of uranium phosphate and that most of them do not contain calcium. These results raise the possibility that during the resorption process, the autunite-like phase identified in the matrix may be bio-transformed into a calcium-free uranium phosphate phase, found internalized in the vesicles of resorbing osteoclasts. It has been suggested that dissolution of autunite minerals under acidic condition leads to the formation of uranyl-phosphate crystals (Wellman et al. 2007). During the resorption process, the extracellular compartment formed between the osteoclast and the bone surface is acidified via proton secretion by the V-ATPase, allowing the apatite to dissolve. Hence, it is tempting to speculate that autunite present in the mineralized matrix could be dissolved in this acidified resorption compartment, resulting in the formation of uranylphosphate crystals potentially internalized in trancytosis vesicles (Fig. 7). U(VI), thus conditioned, could cross osteoclasts to be secreted via the functional secreting domain along with other degradation products.

Vesicles with needle and platelets were not observed in osteoclasts that have resorbed synthetic matrix. This could be explained by the nature of this matrix, which is so thin that resorbing osteoclasts reach very quickly the plastic surface. One hypothesis would be that the actin ring becomes loose under such conditions, and that the degradation products resulting from resorption are then released directly into the extracellular medium without 
undergoing transcytosis.

In conclusion, this study shows that pre-osteoclasts and osteoclasts are particularly sensitive cells to $\mathrm{U}(\mathrm{VI})$, whose function can be stimulated or inhibited depending on the concentration of $\mathrm{U}(\mathrm{VI})$ in the environment. Our results also provide the first evidence, at the cellular level, that resorption contributes to the remobilization of $\mathrm{U}(\mathrm{VI})$. Furthermore, they lead us to propose that $\mathrm{U}(\mathrm{VI})$ cycling in bone would include a transition from an autunite to a uranyl-phosphate phase, which could be promoted by resorption lacunae acidification. Finally, we hereby report a first characterization of $\mathrm{U}(\mathrm{VI})$-containing matrices that could be used as 3D models of the bone microenvironment. These models should be helpful either to further study mechanisms involved in uranium distribution in the skeleton, or to decipher the cellular and molecular mechanisms at play in response to uranium presence in bone. 


\section{References}

Arruda-Neto JDT, Guevara MVM, Nogueira GP, et al (2004) Long-term accumulation of uranium in bones of Wistar rats as a function of intake dosages. Radiat Prot Dosimetry 112:385-393. https://doi.org/10.1093/rpd/nch405

ATSDR (2013) ATSDR - $\quad$ Toxicological Profile: Uranium. http://www.atsdr.cdc.gov/toxprofiles/TP.asp?id=440\&tid=77. Accessed 22 Jul 2016

Basset C, Averseng O, Ferron P-J, et al (2013) Revision of the biodistribution of uranyl in serum: is fetuin-A the major protein target ? Chem Res Toxicol 26:645-653. https://doi.org/10.1021/tx400048u

Bostick WD, Jarabek RJ, Conca JL (1999) Phosphate-induced metal stabilization: Use of apatite and bone char for the removal of soluble radionuclides in authentic and simulated DOE groundwater. Air and Waste 92nd annual meeting and exhibition proceedings

Bourgeois D, Burt-Pichat B, Le Goff X, et al (2015) Micro-distribution of uranium in bone after contamination: new insight into its mechanism of accumulation into bone tissue. Anal Bioanal Chem 407:6619-6625. https://doi.org/10.1007/s00216-0158835-7

Bozal CB, Martinez AB, Cabrini RL, Ubios AM (2005) Effect of ethane-1-hydroxy-1,1bisphosphonate (EHBP) on endochondral ossification lesions induced by a lethal oral dose of uranyl nitrate. Arch Toxicol 79:475-481. https://doi.org/10.1007/s00204005-0649-5

Díaz Sylvester PL, López R, Ubios AM, Cabrini RL (2002) Exposure to subcutaneously implanted uranium dioxide impairs bone formation. Arch Environ Health 57:320325. https://doi.org/10.1080/00039890209601415

Ellender M, Haines JW, Harrison JD (1995) The distribution and retention of plutonium, americium and uranium in CBA/H mice. Hum Exp Toxicol 14:38-48. https://doi.org/10.1177/096032719501400109 
Eriksen EF (2010) Cellular mechanisms of bone remodeling. Rev Endocr Metab Disord 11:219-227. https://doi.org/10.1007/s11154-010-9153-1

Faruqi AF, Rao H, Causer J, Beltzer JP (2011) Corning osteo assay surface for the study of bone resorption. Bone 48:S47. https://doi.org/10.1016/j.bone.2010.10.132

Fukuda S, Ikeda M, Chiba M, Kaneko K (2006) Clinical diagnostic indicators of renal and bone damage in rats intramuscularly injected with depleted uranium. Radiat Prot Dosim 118:307-314. https://doi.org/10.1093/rpd/nci350

Fuller CC, Bargar JR, Davis JA (2003) Molecular-scale characterization of uranium sorption by bone apatite materials for a permeable reactive barrier demonstration. Environ Sci Technol 37:4642-4649. https://doi.org/10.1021/es0343959

Fuller CC, Bargar JR, Davis JA, Piana MJ (2002) Mechanisms of uranium interactions with hydroxyapatite: implications for groundwater remediation. Environ Sci Technol 36:158-165. https://doi.org/10.1021/es0108483

Gigliotti CL, Boggio E, Clemente N, et al (2016) ICOS-Ligand Triggering Impairs Osteoclast Differentiation and Function In Vitro and In Vivo. J Immunol 197:3905-3916. https://doi.org/10.4049/jimmunol.1600424

Gritsaenko T, Pierrefite-Carle V, Creff G, et al (2018) Methods for Analyzing the Impacts of Natural Uranium on In Vitro Osteoclastogenesis. $J$ Vis Exp. https://doi.org/10.3791/56499

Gritsaenko T, Pierrefite-Carle V, Lorivel T, et al (2017) Natural uranium impairs the differentiation and the resorbing function of osteoclasts. Biochim Biophys Acta-Gen Subj 1861:715-726. https://doi.org/10.1016/j.bbagen.2017.01.008

Guglielmotti MB, Ubios AM, Cabrini RL (1985) Alveolar wound healing alteration under uranyl nitrate intoxication. J Oral Pathol Med 14:565-572. https://doi.org/10.1111/j.1600-0714.1985.tb00530.x 
Guglielmotti MB, Ubios AM, de Rey BM, Cabrini RL (1984) Effects of acute intoxication with uranyl nitrate on bone formation. Experientia 40:474-476. https://doi.org/10.1007/BF01952392

Hauge EM, Qvesel D, Eriksen EF, et al (2001) Cancellous bone remodeling occurs in specialized compartments lined by cells expressing osteoblastic markers. J Bone Miner Res 16:1575-1582. https://doi.org/10.1359/jbmr.2001.16.9.1575

Hurault L, Creff G, Hagège A, et al (2019) Uranium Effect on Osteocytic Cells In Vitro. Toxicol Sci 170:199-209. https://doi.org/10.1093/toxsci/kfz087

Huynh T-NS, Vidaud C, Hagège A (2016) Investigation of uranium interactions with calcium phosphate-binding proteins using ICP/MS and CE-ICP/MS. Metallomics 8:11851192. https://doi.org/10.1039/c6mt00147e

Kim HM, Rey C, Glimcher MJ (1995) Isolation of calcium-phosphate crystals of bone by non-aqueous methods at low temperature. J Bone Miner Res 10:1589-1601. https://doi.org/10.1002/jbmr.5650101021

Kurttio P, Komulainen H, Leino A, et al (2005) Bone as a possible target of chemical toxicity of natural uranium in drinking water. Environ Health Persp 113:68-72

Larivière D, Tolmachev SY, Kochermin V, Johnson S (2013) Uranium bone content as an indicator of chronic environmental exposure from drinking water. J Environ Radioact 121:98-103. https://doi.org/10.1016/j.jenvrad.2012.05.026

Leggett RW (1994) Basis for the ICRP's age-specific biokinetic model for uranium. Health Phys 67:589-610

Locock AJ, Burns PC (2003) The crystal structure of synthetic autunite, $\mathrm{Ca}[(\mathrm{UO} 2)(\mathrm{PO} 4)] 2(\mathrm{H} 2 \mathrm{O}) 11$. Am Mineral 88:240-244. https://doi.org/10.2138/am2003-0128

Lutter A-H, Hempel U, Wolf-Brandstetter C, et al (2010) A novel resorption assay for osteoclast functionality based on an osteoblast-derived native extracellular matrix. $\mathrm{J}$ Cell Biochem 109:1025-1032. https://doi.org/10.1002/jcb.22485 
Mehta VS, Maillot F, Wang Z, et al (2016) Effect of Reaction Pathway on the Extent and Mechanism of Uranium(VI) Immobilization with Calcium and Phosphate. Environ Sci Technol 50:3128-3136. https://doi.org/10.1021/acs.est.5b06212

Milgram S, Carrière M, Thiebault C, et al (2008) Cytotoxic and phenotypic effects of uranium and lead on osteoblastic cells are highly dependent on metal speciation. Toxicology 250:62-69. https://doi.org/10.1016/j.tox.2008.06.003

Neuman WF, Neuman MW (1949) The deposition of uranium in bone; adsorption studies in vitro. J Biol Chem 179:325-333

Ng PY, Brigitte Patricia Ribet A, Pavlos NJ (2019) Membrane trafficking in osteoclasts and implications for osteoporosis. Biochem Soc Trans 47:639-650. https://doi.org/10.1042/BST20180445

Pierrefite-Carle V, Santucci-Darmanin S, Breuil V, et al (2016) Effect of natural uranium on the UMR-106 osteoblastic cell line: impairment of the autophagic process as an underlying mechanism of uranium toxicity. Arch Toxicol 91:1903-1914. https://doi.org/10.1007/s00204-016-1833-5

Priest ND, Howells GR, Green D, Haines JW (1982) Uranium in bone: metabolic and autoradiographic studies in the rat. Hum Toxicol 1:97-114

Qi L, Basset C, Averseng O, et al (2014) Characterization of UO2(2+) binding to osteopontin, a highly phosphorylated protein: insights into potential mechanisms of uranyl accumulation in bones. Metallomics 6:166-176. https://doi.org/10.1039/c3mt00269a

Ravel B, Newville M (2005) ATHENA, ARTEMIS, HEPHAESTUS: data analysis for X-ray absorption spectroscopy using IFEFFIT. J Synchrotron Radiat 12:537-541. https://doi.org/10.1107/S0909049505012719

Rehr JJ, Kas JJ, Vila FD, et al (2010) Parameter-free calculations of X-ray spectra with FEFF9. Phys Chem Chem Phys 12:5503-5513. https://doi.org/10.1039/b926434e 
Rodrigues G, Arruda-Neto JDT, Pereira RMR, et al (2013) Uranium deposition in bones of Wistar rats associated with skeleton development. Appl Radiat Isotopes 82:105110. https://doi.org/10.1016/j.apradiso.2013.07.033

Sitaud B, Solari PL, Schlutig S, et al (2012) Characterization of radioactive materials using the MARS beamline at the synchrotron SOLEIL. J Nucl Mater 425:238-243. https://doi.org/10.1016/j.jnucmat.2011.08.017

Su X, Sun K, Cui FZ, Landis WJ (2003) Organization of apatite crystals in human woven bone. Bone 32:150-162. https://doi.org/10.1016/S8756-3282(02)00945-6

Tasat DR, Orona NS, Mandalunis PM, et al (2007) Ultrastructural and metabolic changes in osteoblasts exposed to uranyl nitrate. Arch Toxicol 81:319-326. https://doi.org/10.1007/s00204-006-0165-2

Thakur P, Moore RC, Choppin GR (2009) Sorption of U(VI) species on hydroxyapatite. Radiochim Acta 93:385-391. https://doi.org/10.1524/ract.2005.93.7.385

Ubios AM, Guglielmotti MB, Steimetz T, Cabrini RL (1991) Uranium inhibits bone formation in physiologic alveolar bone modeling and remodeling. Environ Res 54:17-23. https://doi.org/10.1016/S0013-9351(05)80191-4

Vidaud C, Bourgeois D, Meyer D (2012) Bone as target organ for metals: the case of $f$ elements. Chem Res Toxicol 25:1161-1175. https://doi.org/10.1021/tx300064m

Wade-Gueye NM, Delissen O, Gourmelon P, et al (2012) Chronic exposure to natural uranium via drinking water affects bone in growing rats. Biochim Biophys Acta-Gen Subj 1820:1121-1127. https://doi.org/10.1016/j.bbagen.2012.04.019

Wellman DM, Gunderson KM, Icenhower JP, Forrester SW (2007) Dissolution kinetics of synthetic and natural meta-autunite minerals, $\mathrm{X} 3-n(n)+[(\mathrm{UO} 2)(\mathrm{PO} 4)] 2 \cdot x \mathrm{H} 2 \mathrm{O}$, under acidic conditions. Geochem Geophys Geosy 8. https://doi.org/10.1029/2007GC001695 


\section{Figure Captions}

Fig. $1 \mathrm{U}(\mathrm{VI})$ in synthetic apatite matrix. a 24-well COAS plates were incubated for 48 hours with alpha-MEM medium containing the indicated concentrations of uranyl acetate. $\mathrm{U}(\mathrm{VI})$ retained on matrix was quantified by ICP-MS. Data represent the mean \pm SD obtained of 5 independent experiments each performed in duplicate or triplicate. b (Upper panel) Experimental (straight line) and adjusted (dots) EXAFS spectra at the $U$ LIII edge of $U(V I)$ synthetic matrix. The experimental EXAFS spectrum of autunite model is also shown for comparison; (lower panel) corresponding Fourier transforms

Fig. $2 \mathrm{U}(\mathrm{VI})$ release from synthetic matrices. a Schematic illustration of the protocol. Series of matrices containing different amounts of $\mathrm{U}(\mathrm{VI})$ were prepared. A part of them were used for initial $U$ quantification (initial ECM) and another part was seeded on day 0 (D0) with RAW 264.7 cells in the absence or presence of RANKL. On day 3, culture supernatants (D3 supernatant) were harvested to quantify, by ICP/MS, U(VI) potentially released from the matrices and cells were refed with fresh medium (thus free of uranium). On day 4 or 5 , culture media were again collected (D4 or D5 supernatant) to measure $\mathrm{U}(\mathrm{VI})$ that could have been released since the change of medium at D3, the matrices were de-cellularized and also subjected to $\mathrm{U}(\mathrm{VI})$ quantification (final $\mathrm{ECM}$ ). $\mathbf{b} \mathrm{A}$ bar graph shows the release of $\mathrm{U}(\mathrm{VI})$ in culture $\mathrm{D} 3$ and $\mathrm{D} 4$ supernatants as the percent of $\mathrm{U}(\mathrm{VI})$ contained in initial matrices Data are from 2-3 experiments each done in duplicate and given as mean $\pm S D$ if $n=3$, or as mean if $n=2$. c Box plot representations showing minima, first quartile, median, third quartile and maxima of $\mathrm{U}(\mathrm{VI})$ quantification in $\mathrm{D}$ 4 supernatants, according to the presence of RANKL. $\mathrm{U}(\mathrm{VI})$ concentrations used to pre-incubate the matrices are indicated in $\mu \mathrm{M}$ and the average amounts of $\mathrm{U}(\mathrm{VI})$ contained in the resulting matrices are given in $\mu \mathrm{g} /$ well. Data 
are from 2-3 experiments each done in duplicate or triplicate. Each dot represents a replicate. d Box plot representations of the quantification of $\mathrm{U}(\mathrm{VI})$ remaining in synthetic matrices at the end of the culture and after decellularization. ( $n=3$ independent experiments in triplicate). $\mathrm{P}$ values were determined using two-way analysis of variance (ANOVA) with two-stage step-up method of Benjamini, Krieger, and Yekutieli to control the false discovery rate. ${ }^{*} p<0.05 ;{ }^{* *} p<0.01$; na, not applicable (data from 2 experiments); ns, not significant

Fig. 3 Impact of (UVI) on osteoclastic resorption. a To analyze osteoclasts behavior on synthetic matrices containing $\mathrm{U}(\mathrm{VI})$, RAW 264.7 cells were cultured for 4 days in the presence of RANKL on synthetic apatite matrices containing, on average, the indicated amount of $\mathrm{U}(\mathrm{VI})$. Representative processed images of resorbed matrices are shown (resorbed area is in black). Box plot representations show minima, first quartile, median, third quartile and maxima of the relative quantification of resorbed area with median resorbed area in control condition as $100 \% . n=3-4$ independent experiments done in $2-3$ replicates. $\mathbf{b}$ To determine the effect of low $\mathrm{U}(\mathrm{VI})$ concentrations in solution on osteoclasts resorptive activity, RAW 264.7 cells were cultured for 4 days on synthetic apatite matrix, in the presence of RANKL and the indicated concentrations of $U(V I)$ in the culture medium. Representative images of resorbed synthetic matrices and box plot representations of the relative quantification of resorbed area are shown. $n=3-4$ independent experiments each done in 2-4 replicates. $\mathrm{P}$ values were calculated using a two-sided Mann-Whitney test, compared to control condition: $0 \mu \mathrm{MU}(\mathrm{VI}) .{ }^{*} \mathrm{p}<0,05$; ns : not significant

Fig. $4 \mathrm{U}(\mathrm{VI})$-containing biological Saos-2 matrix. Saos-2 cells were cultured in the presence of the indicated concentrations of $\mathrm{U}(\mathrm{VI})$ and under mineralization conditions for 10 days. a 
(Left panel) Representative photograph of calcium deposition as assessed by Alizarin red $\mathrm{S}$ staining. (Right panel) Box plots showing the quantification of calcium deposition. $n=2$ independent experiments with 4 matrices analyzed per experiment and per condition. b Representative scanning electron micrographs of decellularized Saos-2 matrix synthesized in the absence (left panel) or in the presence (right panel) of $\mathrm{U}(\mathrm{VI})$ in the culture medium. c Higher magnification of globular-shaped structures found in Saos-2 matrix in the absence of presence of $\mathrm{U}(\mathrm{VI})$. EDX analyses indicating calcium and phosphate composition of these structures are shown. $\mathbf{d}$ Transmission electronic images showing, in both conditions ( 0 and $2 \mu \mathrm{M}[\mathrm{U}(\mathrm{VI})]$, collagen fibrils (black arrow heads) with their characteristic banding pattern. $\mathbf{e}$ Saos-2 matrices produced in the presence of indicated concentrations of $U(V I)(0,0.5,1$ and $2 \mu \mathrm{M})$ were decellularized after a 10-day culture period and $\mathrm{U}(\mathrm{VI})$ incorporated therein was quantified by ICP-MS. Data represent the mean \pm SD of 4 independent experiments, each performed in duplicate or triplicate. $\mathbf{f}$ (Upper panel) Experimental (straight line) and adjusted (dots) EXAFS spectra at the $U$ LIII edge of $U(V I)$-biological matrix shown with the experimental EXAFS spectrum of autunite model; (lower panel) corresponding Fourier transforms.

Fig. $5 \mathrm{U}(\mathrm{VI})$ release and osteoclasts behavior on Saos-2 extracellular matrices. Decellularized Saos-2 matrices containing the indicated amounts of $\mathrm{U}(\mathrm{VI})$ were seeded with RAW 264.7 cells \pm RANKL. On D3, culture supernatants were harvested and the cells were refed with fresh medium. On D5 the culture medium was again collected and the matrices were subjected to $\mathrm{U}(\mathrm{VI})$ quantification. a $\mathrm{A}$ bar graph shows the release of $\mathrm{U}(\mathrm{VI})$ in $\mathrm{D} 3$ and D5 supernatants as the percent of $\mathrm{U}(\mathrm{VI})$ contained in initial matrices. b Box plots show $\mathrm{U}(\mathrm{VI})$ quantification in D3 (left panel) and D5 (right panel) supernatants according to the 
presence of RANKL. c Box plots presenting the quantification of $\mathrm{U}(\mathrm{VI})$ remaining in Saos-2 matrices at the end of the culture and after decellularization. $n=4$ independent experiments each done in duplicate or triplicate. $\mathrm{P}$ values were determined using two-way analysis of variance (ANOVA) with two-stage step-up method of Benjamini, Krieger, and Yekutieli to control the false discovery rate. d RAW 264.7 cells were cultured with RANKL onto decellularized Saos-2 extracellular matrix, prepared in the presence of the indicated concentration of $\mathrm{U}(\mathrm{VI})$ and containing, on average, the indicated amount of $\mathrm{U}(\mathrm{VI})$. Representative processed images of resorbed Saos-2 matrix are shown. Box plot representations show the relative quantification of resorbed area with median resorbed area in control condition as $100 \% . n=5$ independent experiments each done in $2-3$ replicates. $\mathrm{P}$ values were calculated using a two-sided Mann-Whitney test, compared to control condition: $0 \mu \mathrm{MU}(\mathrm{VI}) .{ }^{*} \mathrm{p}<0,05 ;{ }^{* * *} \mathrm{p}<0.001$; ns : not significant

Fig. 6 TEM and HRTEM-EDX analysis of osteoclasts on a Saos-2 matrix containing U(VI). a TEM micrographs at different magnifications of an osteoclast with a vesicle (white arrow) containing needle- (black arrowheads) and platelet-like structures (white arrowheads) are shown. b High-resolution transmission electron microscopy images of a vesicle are presented. The square areas shown on the central panels have been used for the X-ray microanalysis presented on the left panels showing the components of platelet (spectre 1) and needle (spectre 2) structures or an area of the vesicle free of needles and platelets (spectre 3).

Fig. 7 Hypothetic scheme of the uranium cycle in resorbing osteoclast. Uranium is present in an autunite form in the new mineralized matrix by Saos-2 cells. During the resorption phase, the osteoclast acidifies the actin ring sealed compartment via the V-ATPase action, 
and the low $\mathrm{pH}$ could favor the transition of autunite to a U-phosphate form. The degradation products including the U-phosphate platelets and needles would than move across the osteoclast in transcytosis vesicles prior to be released in the external media. The osteoclast resorption function can be stimulated or repressed depending on the $U(V I)$ concentration present in the external media. 

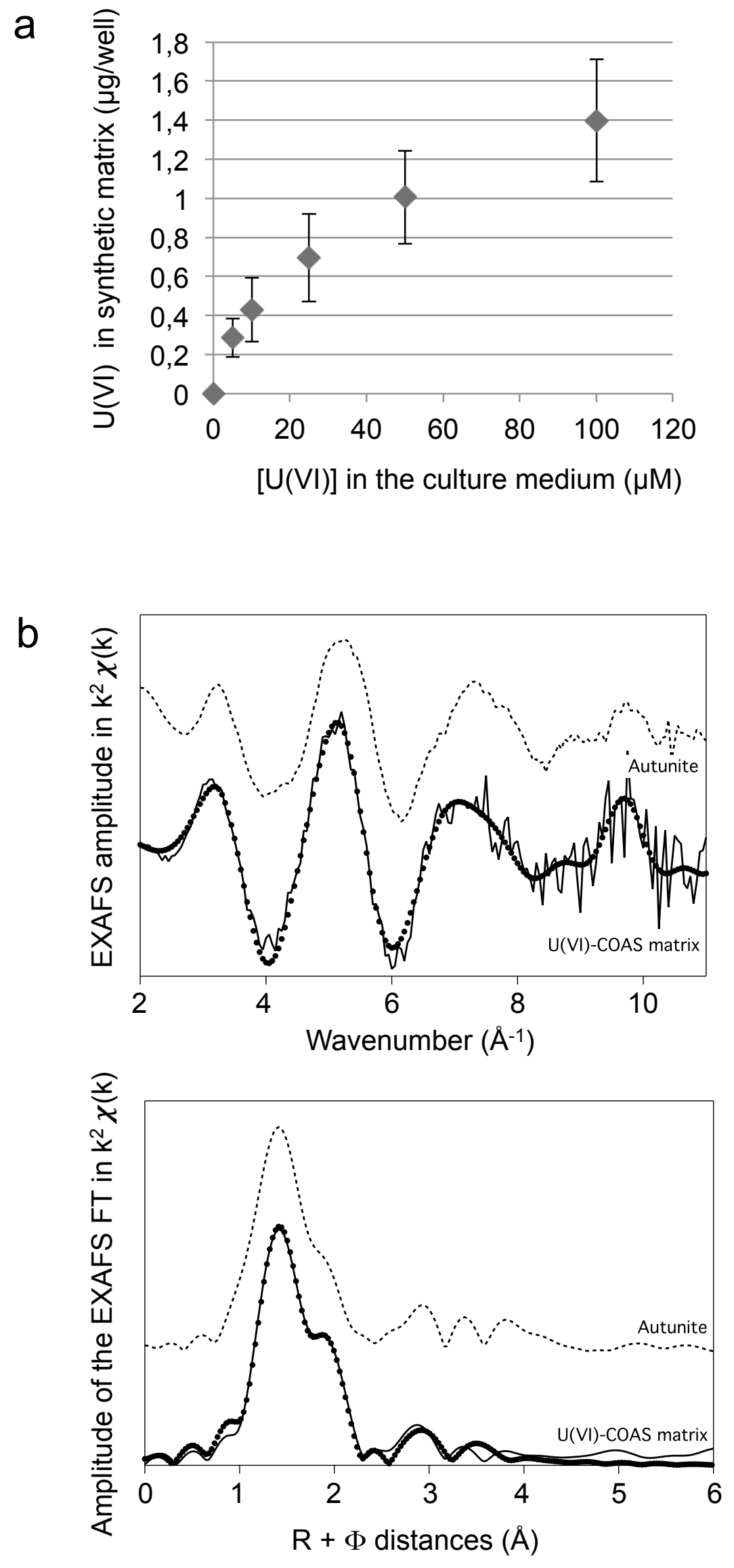


\section{initial ECM production}

a

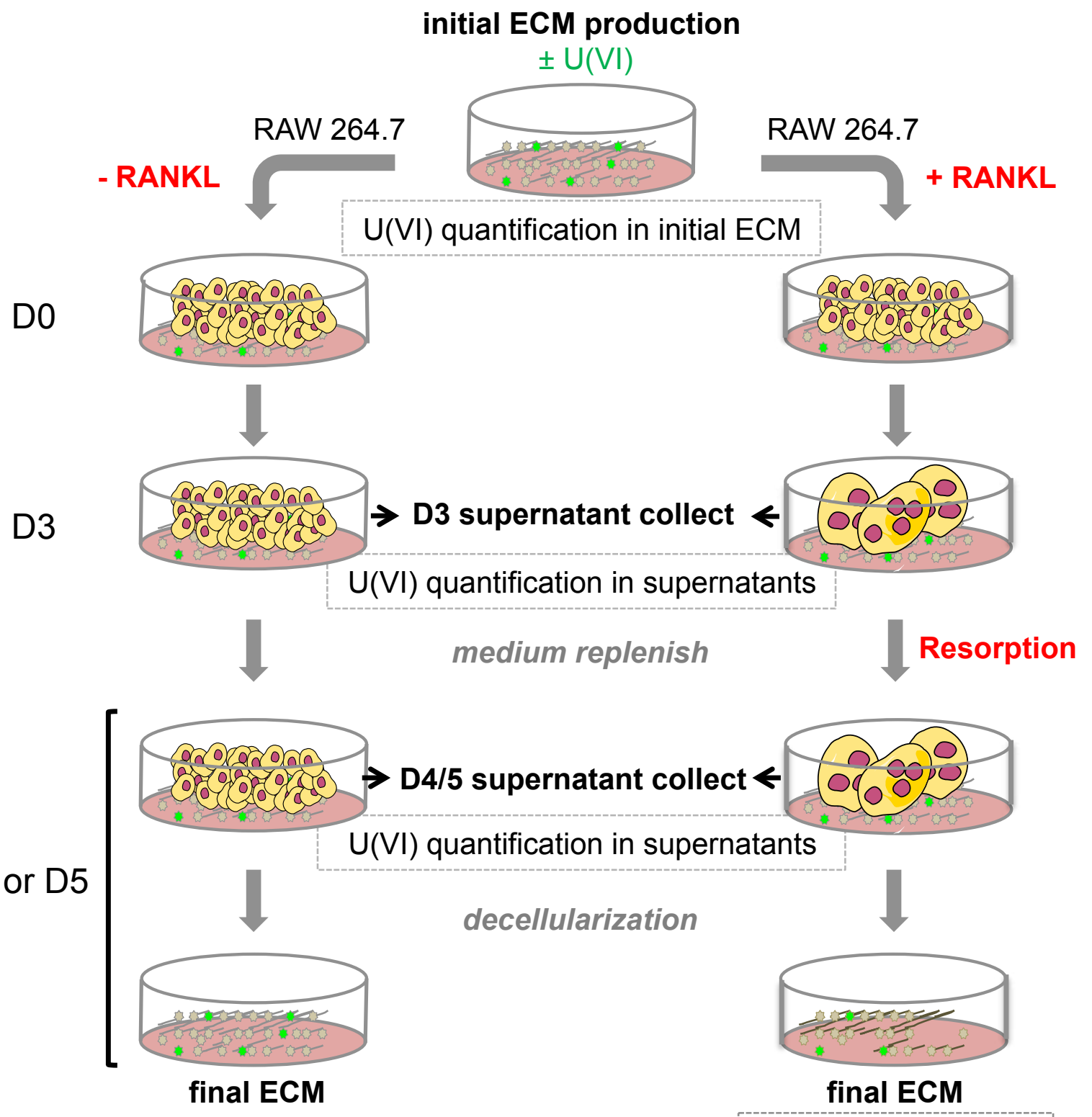

Resorption analysis

$\mathrm{U}(\mathrm{VI})$ quantification in final ECM 
b

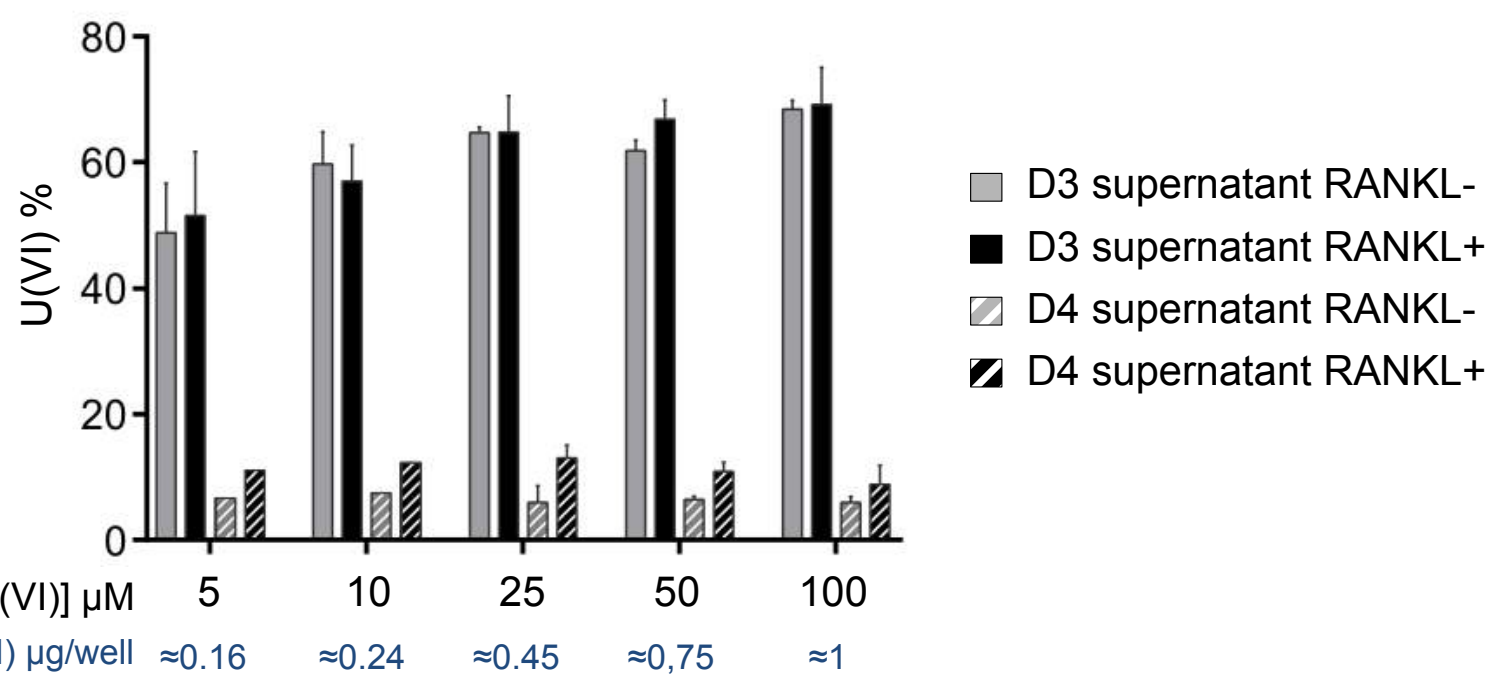

C

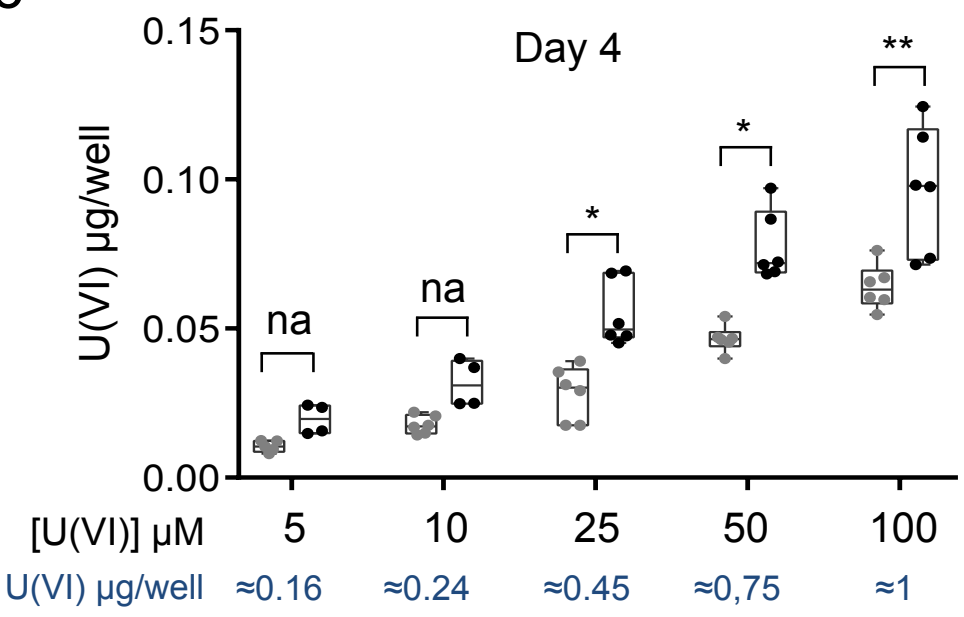

d




a


$[\mathrm{U}(\mathrm{VI})](\mu \mathrm{M}) 0$

5

$\mathrm{U}(\mathrm{VI})(\mu \mathrm{g} / \mathrm{well}) 0$

$\approx 0.16$

10

25

50

100

$\approx 0,75$

$\approx 1$

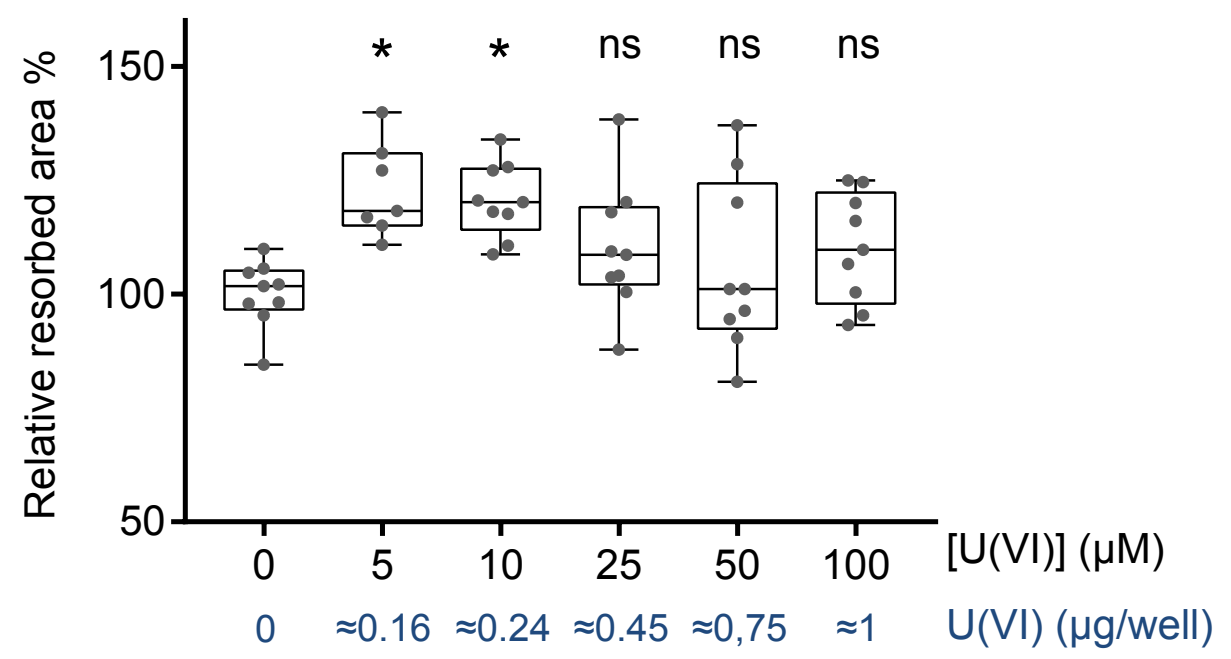

b

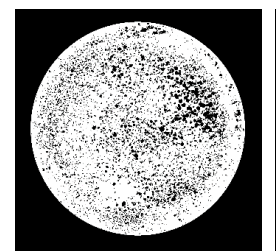

$[\mathrm{U}(\mathrm{VI})] \mu \mathrm{M} \quad 0$

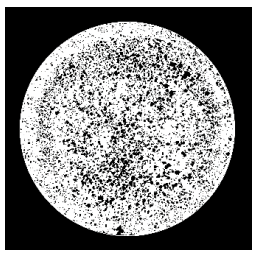

0,25

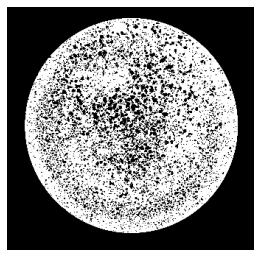

0,5

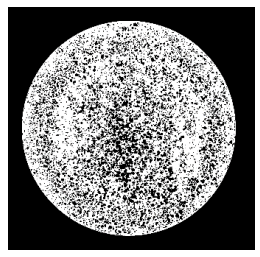

1

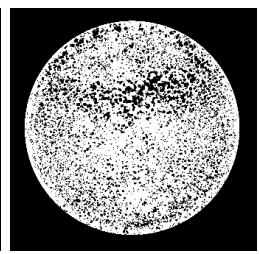

3

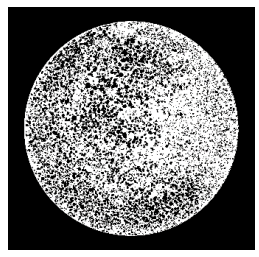

5

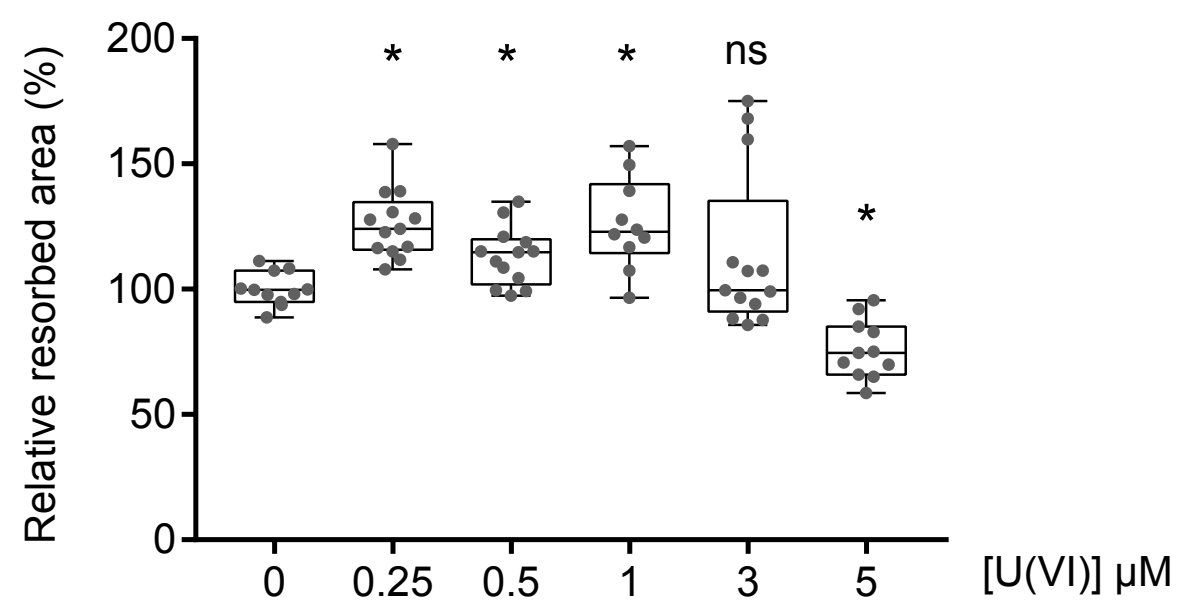


a

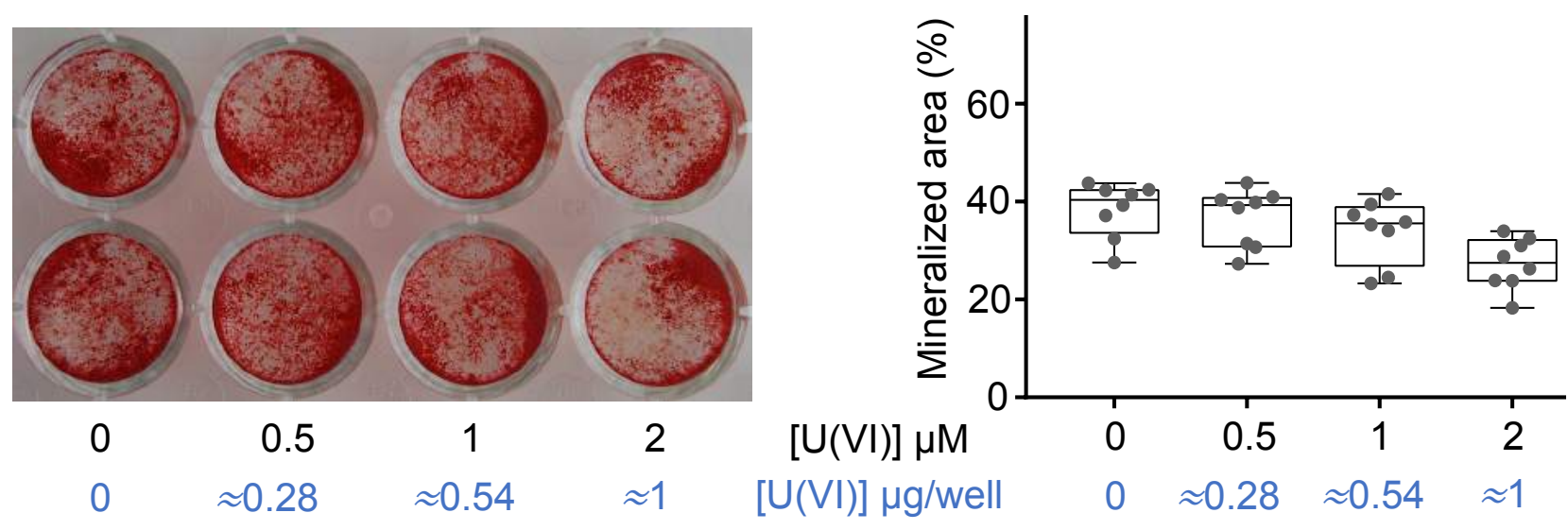

b

$$
[\mathrm{U}(\mathrm{VI})]=0 \mu \mathrm{M}
$$

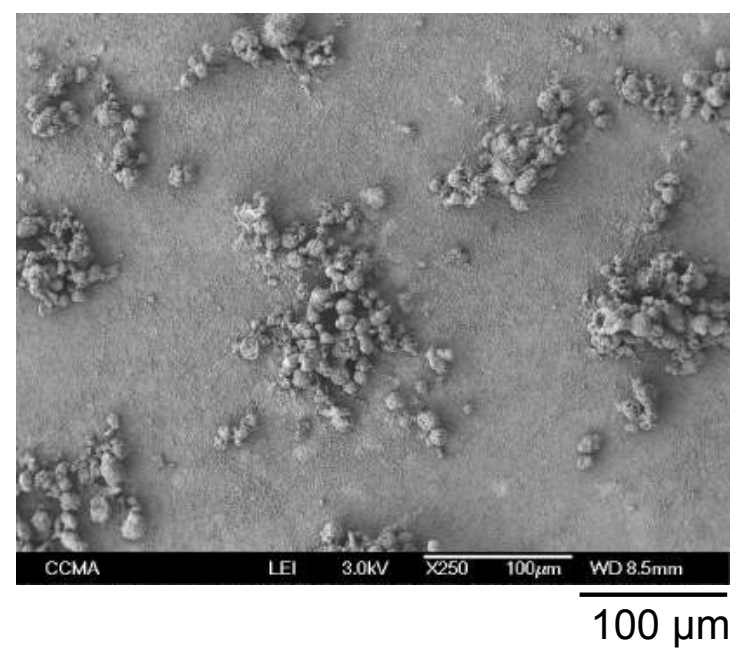

$[\mathrm{U}(\mathrm{VI})]=2 \mu \mathrm{M}$

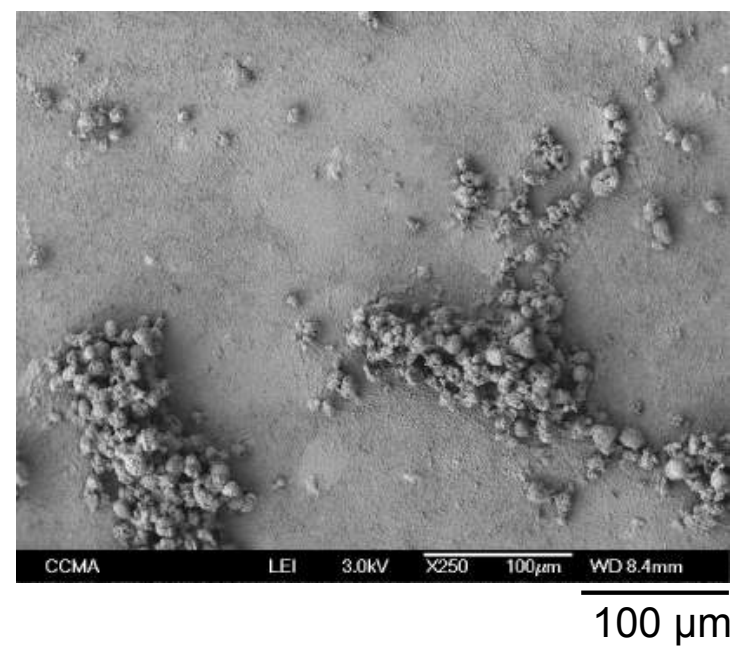



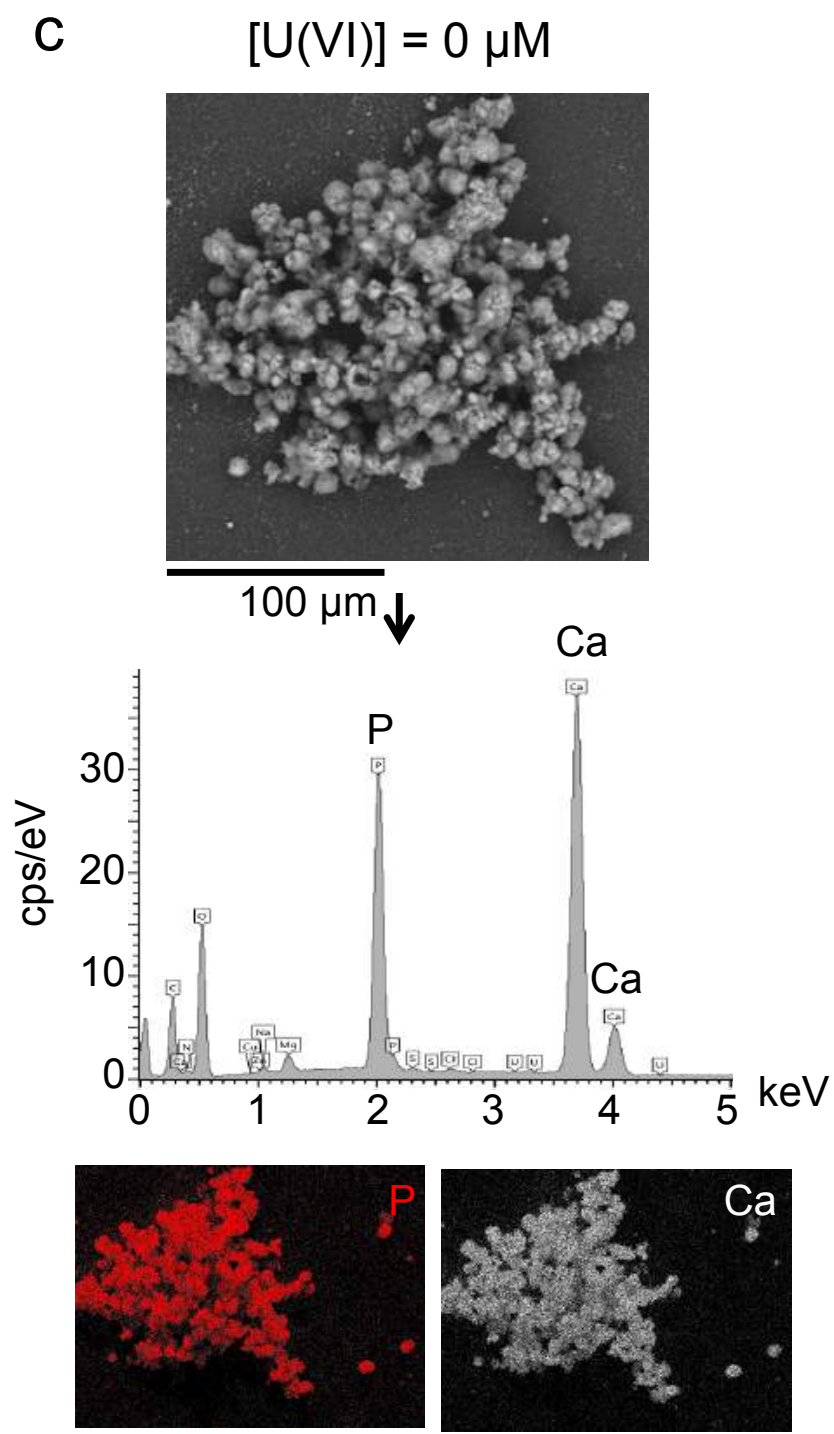

d



$[\mathrm{U}(\mathrm{VI})]=2 \mu \mathrm{M}$
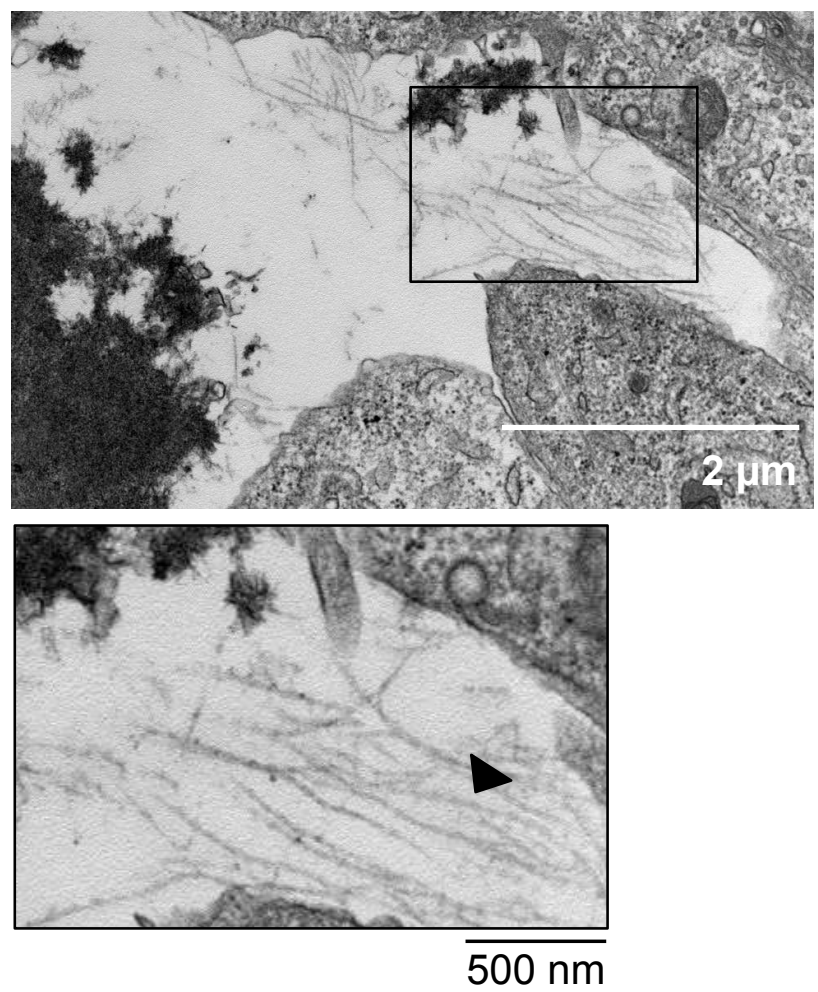
e

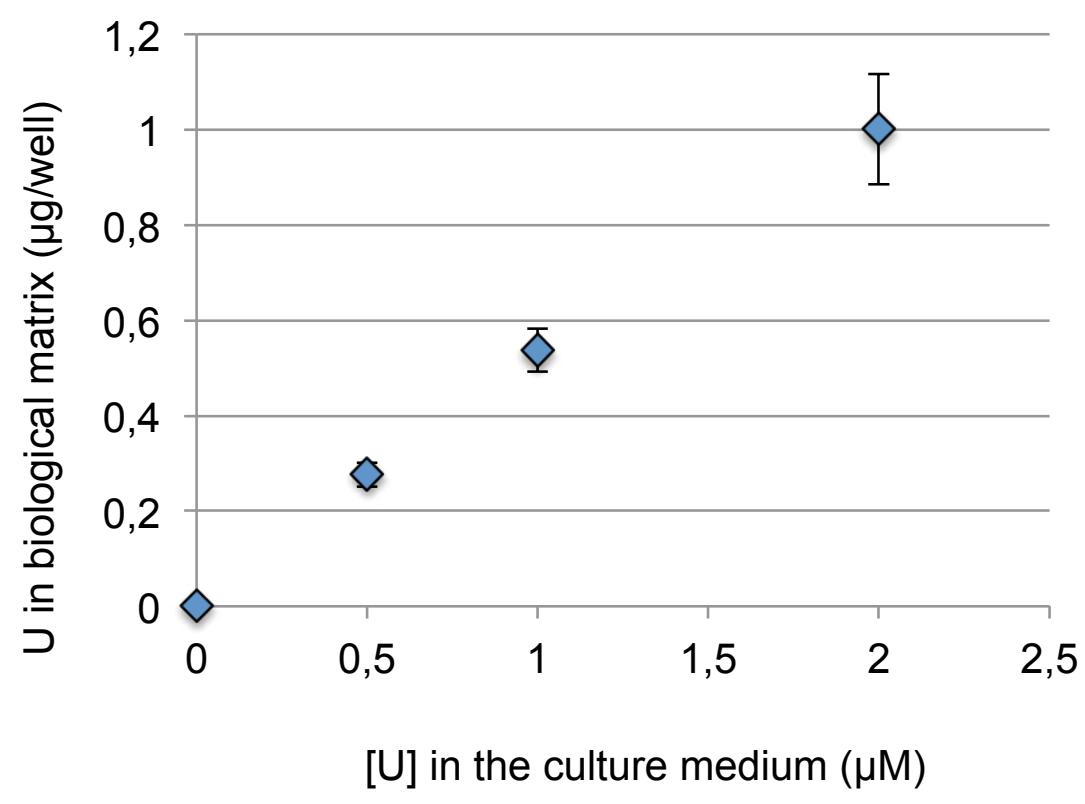

f
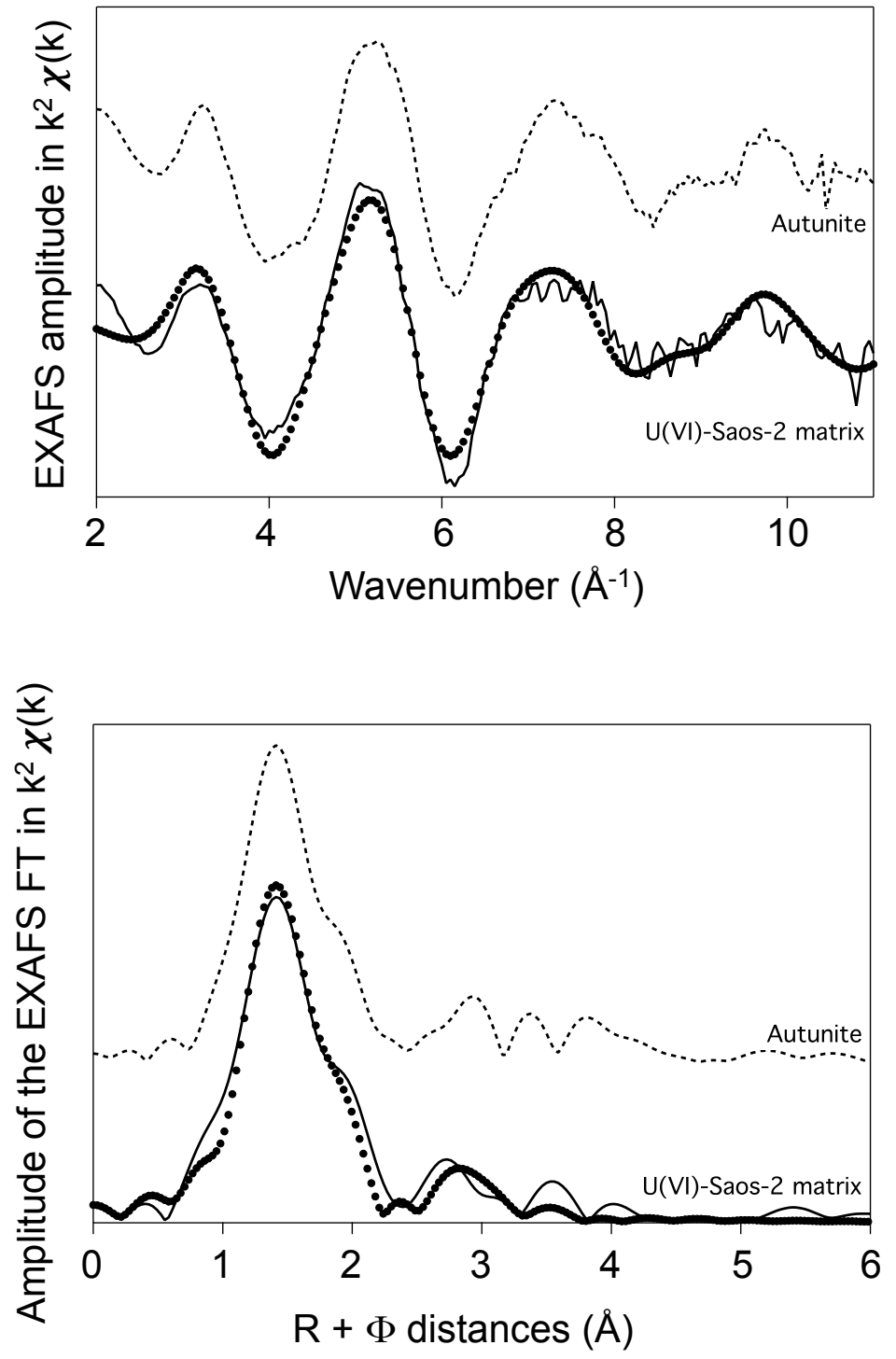
a

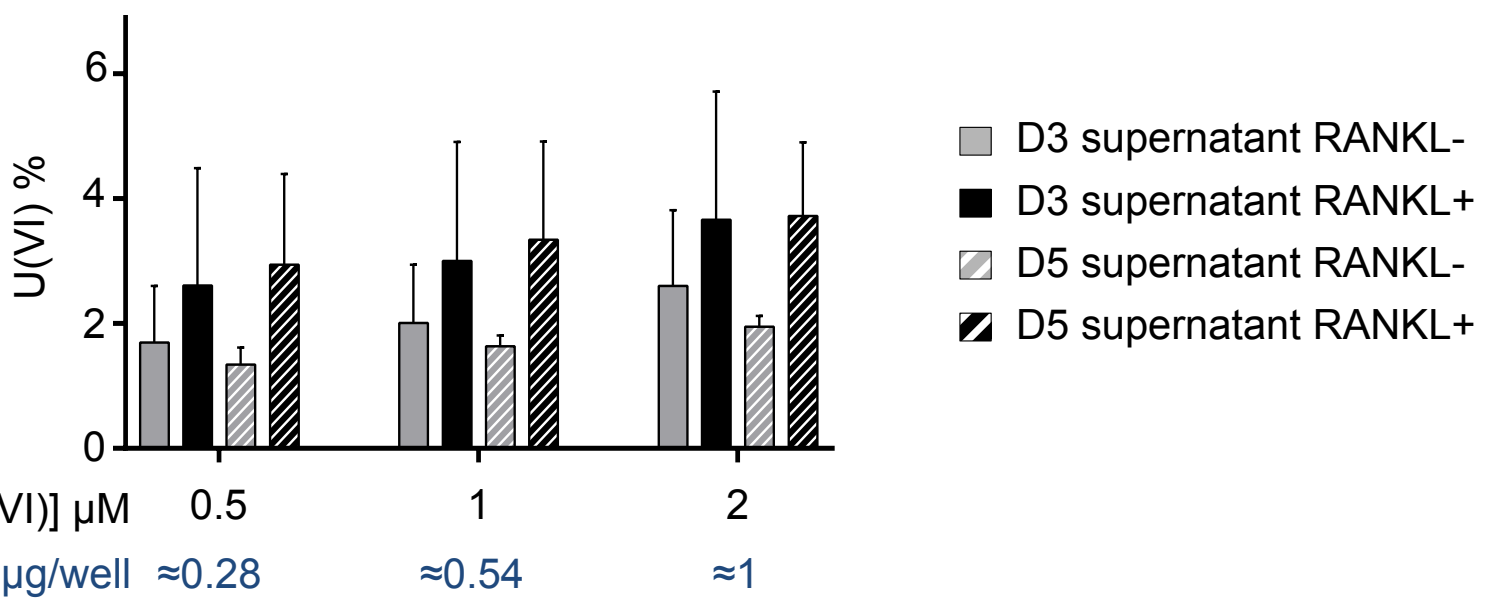

b

Day 3

Day 5
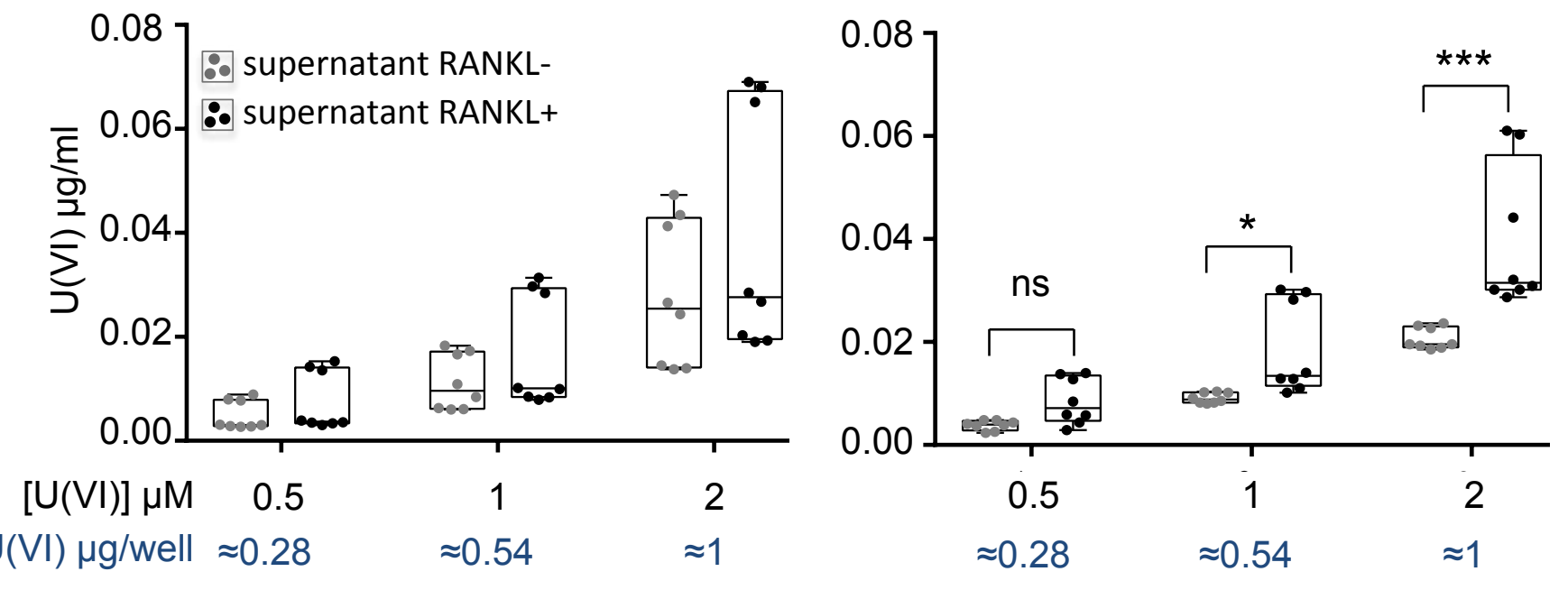

C

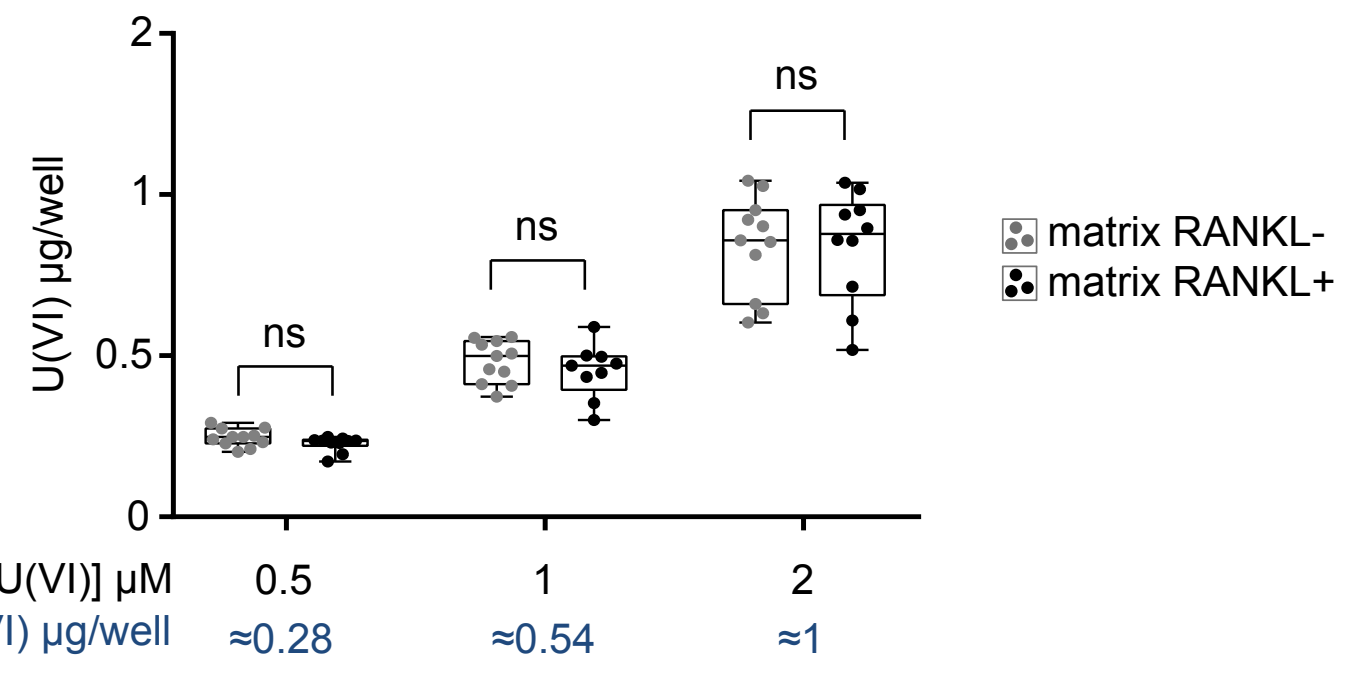

$\mathrm{U}(\mathrm{VI}) \mu \mathrm{g} / \mathrm{well} \quad \approx 0.28 \quad \approx 0.54 \quad \approx 1$


d
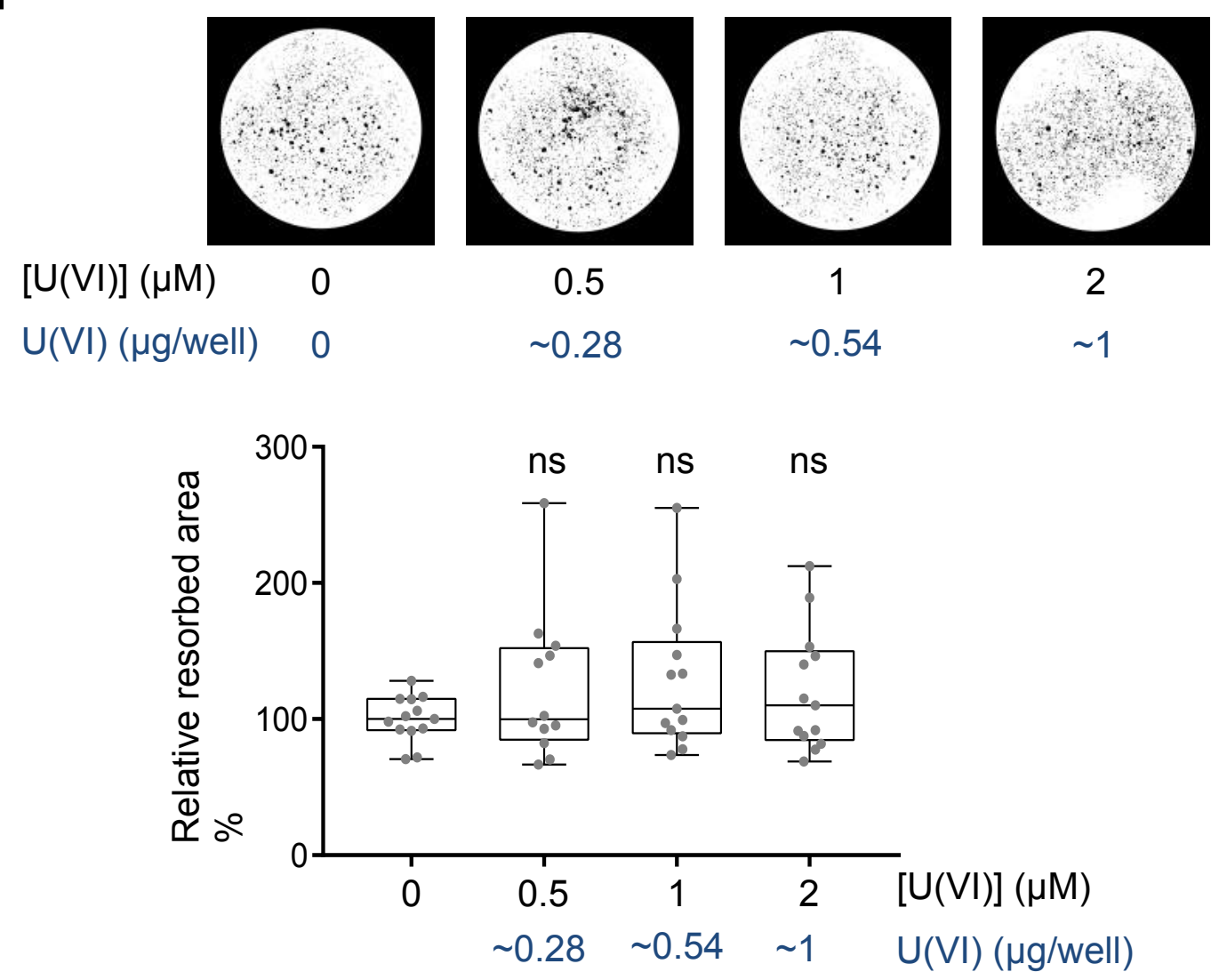
Figure 7

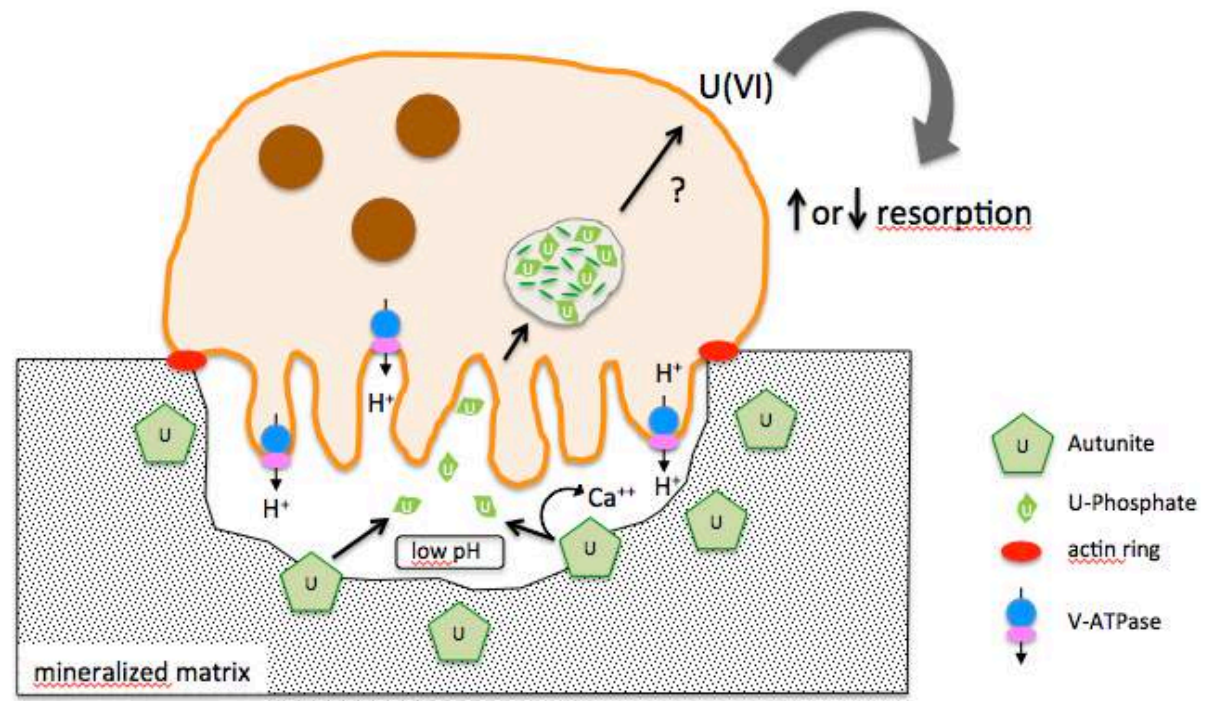


